\title{
Dlx-Dependent and -Independent Regulation of Olfactory Bulb Interneuron Differentiation
}

\author{
Jason E. Long, ${ }^{1}$ Sonia Garel, ${ }^{1,3}$ Manuel Alvarez-Dolado, ${ }^{2,4}$ Kazuaki Yoshikawa, ${ }^{5}$ Noriko Osumi, ${ }^{6}$ Arturo Alvarez-Buylla, ${ }^{2}$ \\ and John L. R. Rubenstein ${ }^{1}$ \\ ${ }^{1}$ Nina Ireland Laboratory of Developmental Neurobiology and²Department of Neurological Surgery and Developmental and Stem Cell Biology Program, \\ University of California at San Francisco, San Francisco, California 94143, ${ }^{3}$ Institut National de la Santé et de la Recherche Médicale, Unité 784, École \\ Normale Supérieure, 75230 Paris cedex 05, France, ${ }^{4}$ Laboratorio de Regeneración Celular, Centro Investigación Príncipe Felipe, 46013 Valencia, Spain, \\ ${ }^{5}$ Laboratory of Regulation of Neuronal Development, Institute for Protein Research, Osaka University, Suita, Osaka 565-0871, Japan, and ${ }^{6}$ Division of \\ Developmental Neuroscience, Center for Translational and Advanced Animal Research, Tohoku University Graduate School of Medicine, Sendai 980-8575, \\ Japan
}

Olfactory bulb interneuron development is a complex multistep process that involves cell specification in the ventral telencephalon, tangential migration into the olfactory bulb, and local neuronal maturation. Although several transcription factors have been implicated in this process, how or when they act remains to be elucidated. Here we explore the mechanisms that result in olfactory bulb interneuron defects in Dlx1\& $2^{-/-}$(distal-less homeobox 1 and 2) and Mash1 $1^{-/-}$(mammalian achaete-schute homolog 1) mutants. We provide evidence that $D l x 1 \& 2$ and Mash1 regulate parallel molecular pathways that are required for the generation of these cells, thereby providing new insights into the mechanisms underlying olfactory bulb development. The analysis also defined distinct anatomical zones related to olfactory bulb development. Finally we show that $D l x 1 \& 2$ are required for promoting tangential migration to the olfactory bulb, potentially via regulating the expression of ErbB4 (v-erb-a erythroblastic leukemia viral oncogene homolog 4), Robo2 (roundabout homolog 2), Slit1 (slit homolog 1), and PK2 (prokineticin 2), which have all been shown to play essential roles in this migration.

Key words: GABA; interneuron; migration; olfactory bulb; forebrain; development

\section{Introduction}

The tangential migration of immature interneurons produced in the mouse basal ganglia anlage (subpallium) plays a major role in the development of pallial structures, including the neocortex, hippocampus, and olfactory bulb (OB). Most of these neurons originate in the caudal (CGE), lateral (LGE), and medial (MGE) ganglionic eminences (Marin and Rubenstein, 2001, 2003; Tucker et al., 2006; Wonders and Anderson, 2006). There is evidence that dorsal parts of the LGE (dLGE) are specifically involved in producing $\mathrm{OB}$ interneurons [granule and periglomerular (PG) neurons] that express distinct transcription factors Dlx1,2\&5 (distal-less homeobox 1, 2, and 5), ER81 (ETS domain protein), and Sp8 (Sp8 transcription factor) (for GABAergic neurons) and Pax6 (paired box gene 6) (for dopaminergic neurons) (Long et al., 2003; Stenman et al., 2003; Kohwi et al., 2005; Yun et al., 2003). Furthermore, the septum (SE) may also be a source of embryonic OB interneurons (Long et al., 2003). OB projection neurons (mitral and tufted cells) appear to be produced by pallial

Received Dec. 5, 2006; revised Feb. 7, 2007; accepted Feb. 12, 2007.

This work was supported by the research grants to J.L.R.R. from the following: the Nina Ireland Foundation, the Larry L. Hillblom Foundation, and National Institute of Mental Health Grants R01 MH49428-01 and K05 MH065670. S.G. is a recipient of the Human Frontier Science Program Organization Career Development Award.

Correspondence should be addressed to John L. R. Rubenstein, University of California at San Francisco, 1550 4th Street, 2nd Floor South, Room GD 282, San Francisco, CA 94158-2324. E-mail: john.rubenstein@ucsf.edu. D0I:10.1523/JNEUROSC1.5265-06.2007

Copyright $\odot 2007$ Society for Neuroscience $\quad$ 0270-6474/07/273230-14\$15.00/0 progenitors that require the function of a distinct set of transcription factors, including Tbr1 (T-box brain gene 1) (Bulfone et al., 1998).

Whereas migrations to the cortex and hippocampus are primarily prenatal processes in rodents, migration to the $\mathrm{OB}$ along the rostral migratory stream (RMS) continues in adults (Luskin, 1993; Lois and Alvarez-Buylla, 1994; Luskin and Boone, 1994; Doetsch and Alvarez-Buylla, 1996; Lois et al., 1996; Tucker et al., 2006). In adult rodents, immature interneurons originate within the complex network of the adult subventricular zone (SVZ), migrate tangentially to the anterior SVZ, and then continue migration in the RMS toward the OB. On reaching the OB, these neurons change orientation to migrate radially to populate the granule cell and periglomerular layers. They then further differentiate into local circuit neurons.

The molecules that regulate the specification, differentiation, and migration of $\mathrm{OB}$ interneurons are beginning to be elucidated, including a set of transcription factors: Dlx1,2,5\&6, Gsh $\& 2$ (genomic screened homeobox 1 and 2), Mash1 (mammalian achaete-schute homolog 1), Pax6, and Sp8. The Gsh1\&2 homeobox genes are among the earliest markers of ventricular zone (VZ) progenitors that produce telencephalic GABAergic neurons. These genes are required to produce $\mathrm{OB}$ interneurons through specifying progenitor domain identity (Corbin et al., 2000; Toresson et al., 2000, 2001; Yun et al., 2001, 2003). Mash1 encodes a basic helix-loop-helix transcription factor that is also 
expressed in the subpallial VZ (and SVZ), in which it is required for controlling the balance between early and late progenitors and for the efficient generation of GABAergic neurons (Casarosa et al., 1999; Horton et al., 1999; Yun et al., 2002).

The Dlx1,2,5\&6 homeobox genes begin expression after Gsh1\&2 and Mash1 (Yun et al., 2002, 2003); Dlx2 is expressed in a subset of VZ cells; all four $D l x$ genes are strongly expressed in the SVZ, and subsets of $D l x$ genes are expressed in differentiating forebrain GABAergic and dopaminergic neurons (Eisenstat et al., 1999; Long et al., 2003). Postnatally, Dlx2 and Mash1 are expressed in the adult SVZ and RMS in transient amplifying cells and neuroblasts (Porteus et al., 1994; Doetsch et al., 2002; Parras et al., 2004). Dlx1\& $2^{-/-}$mice lack virtually all OB GABAergic and dopaminergic interneurons (Bulfone et al., 1998), whereas $D l \times 1^{-1-}, D l \times 2^{-1-}$, or $D l x 5^{-/-}$mutants have less severe OB phenotypes (Qiu et al., 1995; Long et al., 2003) (J.E.L. and J.L.R.R., unpublished observation).

In addition to the early role of Pax6 in patterning the OB anlage (Anchan et al., 1997; Jimenez et al., 2000; Nomura and Osumi, 2004; Nomura et al., 2006), this paired-homeobox gene has a later role for generating dopaminergic periglomerular interneurons and is implicated in regulating development of superficial granule cells (Dellovade et al., 1998; Hack et al., 2005; Kohwi et al., 2005). The $S p 8$ zinc-finger gene is expressed in and required for the differentiation of GABA-positive $\left(\mathrm{GABA}^{+}\right)$and calreti$\operatorname{nin}^{+}$periglomerular cells (Waclaw et al., 2006). ER81, an ETS transcription factor, shares an expression pattern similar to $S p 8$ in the dLGE, but the function of ER81 in these cells is unknown (Stenman et al., 2003).

Very little is known about how these transcription factors regulate $\mathrm{OB}$ interneuron development. Given the function of the Dlx genes in controlling migration of MGE-derived interneurons (Anderson et al., 1997a, 2001), it is possible that they modulate the expression of molecules that control migration of immature OB interneurons. SLIT ligands and the ROBO (roundabout homolog) receptors are currently considered to be among the most important regulators of $\mathrm{OB}$ interneuron migration. SLIT proteins have been shown to repel migrating $\mathrm{OB}$ interneurons $(\mathrm{Hu}$, 1999; Li et al., 1999; Wu et al., 1999; Chen et al., 2001; Sawamoto et al., 2006) and to also have cell-autonomous functions (Nguyen-Ba-Charvet et al., 2004). There is also evidence that a SLIT gradient within the lateral ventricles guides interneuron migration toward the OB. Furthermore, Slit $1 \& 2^{-/-}$(slit homolog 1 and 2) mutants have small OBs (Sawamoto et al., 2006).

Neuregulin signaling is another important regulator of $\mathrm{OB}$ interneuron migration, because ErbB4 ${ }^{-/-}$(v-erb-a erythroblastic leukemia viral oncogene homolog 4) mutants have altered neuroblast chain organization and migration (Anton et al., 2004). These mutants also show deficits in the placement and differentiation of olfactory interneurons. Furthermore, receptor tyrosine kinase signaling through ErbB4/neuregulin and epidermal growth factor (EGF) receptor/EGF promote proliferation of OB interneuron precursors (Doetsch et al., 2002; Ghashghaei et al., 2006). Signaling of the secreted protein prokineticin 2 (PK2) can act as a chemoattractant for OB interneurons; $P K 2^{-/-} \mathrm{mu}-$ tants have a disorganized $\mathrm{OB}$ and show defects in RMS migration (Ng et al., 2005). Secretion of REELIN from mitral cells is implicated as a detachment signal of tangentially migrating OB interneurons (Hack et al., 2002).

Here we explore the mechanisms that result in olfactory bulb interneuron defects in Dlx $\& 2^{-1-}$ and Mash1 $1^{-1-}$ mutants. We provide evidence that $D l x 1 \& 2$ and Mash 1 regulate parallel pathways that are required for the generation of these cells. Dlx1 22 are required for promoting expression of glutamic acid decarboxylase GAD67 (GAD1), vesicular GABA transporter [VGAT (or Viaat for vesicular inhibitory amino acid transporter)], and the ER81 transcription factor; they repress expression of Mash1, Hes5 (hairy and enhancer of split 5), Sp9, and PK2. Conversely, Mash1 has complementary function in promoting expression of $S p 9$ and $P K 2$. Furthermore, $D l x 1 \& 2$ are required for promoting tangential migration to the $\mathrm{OB}$ and may do so through positively regulating expression of ErbB4 and Robo2 and negatively regulating Slit1 and PK2 expression.

\section{Materials and Methods}

Animals and tissue preparation. A mouse mutant strain with a null allele of Dlxl 22 was used in this study (Anderson et al., 1997b; Qiu et al., 1997). This mouse strain was maintained by backcrossing to C57BL/6J mice for more than 10 generations. For staging of embryos, midday of the vaginal plug was calculated as embryonic day 0.5 (E0.5). Mouse colonies were maintained in accordance with the protocols approved by the Committee on Animal Research at University of California, San Francisco. Animals expected to contain Mash1 $1^{-1-}$ and Dlx1 $\mathrm{e} 2^{-/-}$mutant embryos were removed by cesarean section. PCR was performed as described previously (Bulfone et al., 1993; Anderson et al., 1997b; Qiu et al., 1997; Depew et al., 1999; Parras et al., 2002) to genotype offspring resulting from Dlxl\&2 and Mash 1 heterozygous matings. Because no differences in the phenotypes of $D l x 1 \nLeftarrow 2^{+/+}$and $D l x 1 \leftrightarrow 2^{+/-}$brains have been detected, they were both used as controls. Embryos were anesthetized by cooling, dissected, and immersion fixed in $4 \%$ paraformaldehyde (PFA) in PBS for 4-12 h. Samples were either cryoprotected in a gradient of sucrose to $30 \%$, frozen in embedding medium (OCT; Tissue-Tek, Torrance, $\mathrm{CA}$ ), and cut using a cryostat or dehydrated in ethanol, embedded in paraffin, and cut using a microtome.

In situ hybridization. In situ hybridization experiments were performed using ${ }^{35} \mathrm{~S}$ riboprobes on $10 \mu \mathrm{m}$ frozen sections as described previously (Bulfone et al., 1993) or using digoxigenin riboprobes on 20 $\mu \mathrm{m}$ frozen sections as described previously. We generously thank the following people for cDNAs: Drs. Brian Condie (University of Georgia, Athens, GA) for GAD67, Peter Gruss (Max Planck Institute, Munich, Germany) for Pax6, Tom Curran (University of Pennsylvania, Philadelphia, PA) for Reelin, Francois Guillemot (NIMR Medical Research Council, London, UK) for Mash1 and Hes5, Qun-Yong Zhou (University of California at Irvine, Irvine, CA) for PK2, Juan Carlos Izpisúa Belmonte (Salk Institute, La Jolla, CA) for $S p 8$ and $S p$ 9, Tom Jessell (Columbia University, New York, NY) for ER81, Marc Tessier-Lavigne (Genentech, South San Francisco, CA) for Robo1, Robo2, and Slit1, and Cary Lai (Scripps Institute, La Jolla, CA) for ErbB4. The Dlx1, Dlx2, and Dlx5 plasmids were generated in the Rubenstein laboratory.

Histochemistry. Samples were sectioned at $10 \mu \mathrm{m}$ and mounted onto SuperFrost Plus slides (Fisher, Pittsburgh, PA). Sections were stained with cresyl violet (E14.5 to postnatal day 0 ) on OCT-embedded sections and analyzed.

Immunohistochemistry. Immunohistochemistry was performed as described previously (Marin et al., 2000). We used the following primary rabbit polyclonal antibody: anti-PAX6 (diluted 1:250) (Inoue et al., 2000); and guinea pig polyclonal antibody, anti-DLX2 (diluted 1:2000) (Kuwajima et al., 2006). Both the DLX2 and PAX6 antibodies do not show specific immunoreactivity with the mouse forebrain of $D l \times 1 / 2^{-/-}$ and $\mathrm{Pax6}^{-/-}$mutants (see Fig. 4 and data not shown, respectively).

Slice culture. Brains were dissected in ice-cold Krebs' buffer as described previously (Marin et al., 2000) and embedded in 5\% lowmelting-point agarose (FMC Bioproducts, Rockland, MA), and $250 \mu \mathrm{m}$ sagittal sections were cut with a vibrating microtome (VT1000S; Leica, Nussloch, Germany). Slices were then placed onto Transwell membranes ( $8 \mu \mathrm{m}$ pore size, $24 \mathrm{~mm}$ diameter membrane; Costar, Acton, MA) that were previously coated with $1 \mathrm{mg} / \mathrm{ml}$ of Vitrogen (Cohesion, Palo Alto, CA) for $1 \mathrm{~h}$. The Transwell membranes containing the slices were placed into Neurobasal media containing 2\% B-27 supplement (LTI, Gaithersburg, MD), $0.5 \%$ glucose, $2 \%$ glutamine, and $2 \%$ penicillin/streptomycin. A crystal of the axonal tracer, 1,1'-dioctodecyl-3,3,3',3'- 

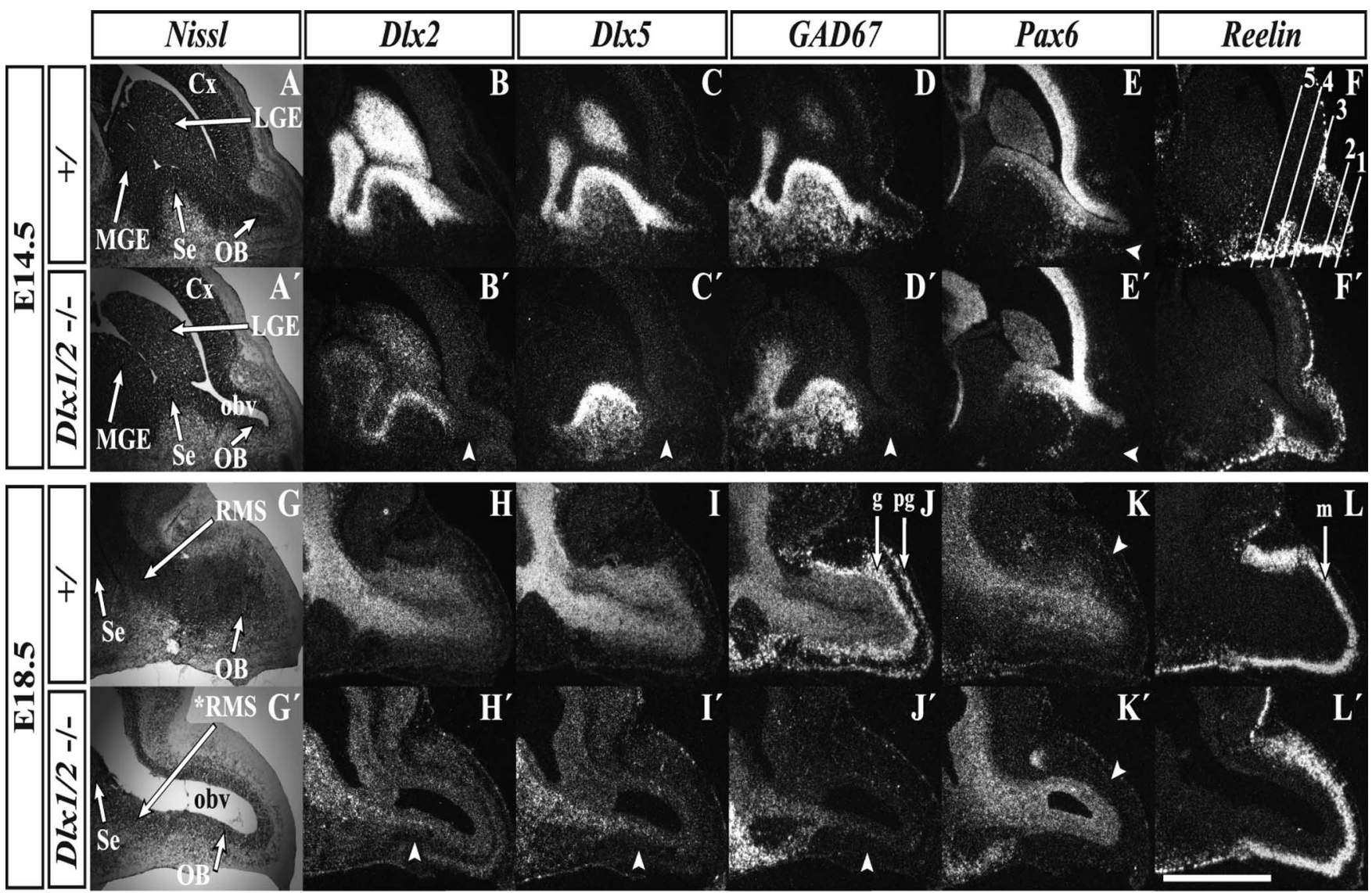

Figure 1. $\quad E 14.5$ and $E 18.5 D / x 1 \& 2^{-/-}$mutant embryos show an enlarged $O B$ ventricle and reduced $O B$ gene expression. At E14.5, Nissl staining of sagittal sections reveals an enlarged $O B$ ventricle in the $D / x 1 \& 2^{-/-}$mutants $\left(\boldsymbol{A}, \boldsymbol{A}^{\prime}\right)$, which is further expanded at E18.5 $\left(\mathbf{G}, \mathbf{G}^{\prime}\right)$. Radioactive in situ RNA hybridization analysis of $D / x 2^{m}$ (a Dlx2 transcript that is expressed in the $D / x 1 \& 2$ mutant) shows a great reduction in the mutant $\mathrm{OB}$ at both $\mathrm{E} 14.5$ (arrowhead, $\left.\boldsymbol{B}, \boldsymbol{B}^{\prime}\right)$ and E18.5 (arrowhead, $\boldsymbol{H}, \boldsymbol{H}^{\prime}$ ). The same is true for $\mathrm{Dlx5}\left(\boldsymbol{C}, \boldsymbol{C}^{\prime}, \boldsymbol{I}, \boldsymbol{I}^{\prime}\right)$ and $G A D 67\left(\mathbf{D}, \mathbf{D}^{\prime}, \boldsymbol{J}, \boldsymbol{J}^{\prime}\right)$. Expression of Pax6 is reduced in the DIx $1 \& 2^{-1-}$ mantle zone of the $0 B$ at E14.5 (arrowhead, $\left.\boldsymbol{E}, \boldsymbol{E}^{\prime}\right)$ and E18.5 (arrowhead, $\left.\boldsymbol{K}, \boldsymbol{K}^{\prime}\right)$. An arrowhead points to the Pax $6^{+}$periglomerular layer $\left(\boldsymbol{K}, \boldsymbol{K}^{\prime}\right)$. Reelin expression (a marker of $0 B$ projection neurons) appears normal in $D I x 1 \& 2^{-1-}$ mutants $\left(\boldsymbol{F}, \boldsymbol{F}^{\prime}, \boldsymbol{L}, \boldsymbol{L}^{\prime}\right)$. Lines in $\boldsymbol{F}$ demarcate numbered coronal section planes (zones $\left.I-V\right)$ in Figures 3 and 8 . C $(x, C$ ortex; $g$, granule cell layer; $\mathrm{m}$, mitral cell layer; $\mathrm{OBv}$ : olfactory bulb ventricle; $\mathrm{pg}$, periglomerular cell layer; ${ }^{*} \mathrm{RMS}$, defective rostral migratory stream. Scale bar: $A-\boldsymbol{L}^{\prime}, 720 \mu \mathrm{m}$.

tetramethylindocarbocyanine perchlorate (DiI) (Invitrogen, Carlsbad, $\mathrm{CA}$ ), was placed into the RMS. The slices were placed in a $37^{\circ} \mathrm{C}$ incubator with $5 \% \mathrm{CO}_{2}$ for $72 \mathrm{~h}$. The slices were then analyzed with fluorescence microscopy for DiI-labeled cells that had migrated beyond the diffusion range of the crystal.

Matrigel assay. Embryos were collected and processed as above for slices. A tungsten needle was used to dissect out a small piece from the subventricular zone of the lateral ganglionic eminence. This small piece was then placed onto a $25 \mu \mathrm{l}$ pad of Matrigel (Becton Dickinson, Bedford, MA). Then $30 \mu \mathrm{l}$ of Matrigel was placed on top of the explant and cultured in Neurobasal media containing 2\% B-27 supplement (LTI), $0.5 \%$ glucose, $2 \%$ glutamine, and $2 \%$ penicillin/streptomycin for $72 \mathrm{~h}$. The explants were fixed for $2 \mathrm{~h}$ in $4 \%$ PFA, immersed in $50 \mu \mathrm{g} / \mathrm{ml}$ Hoechst 33342 (Invitrogen), and mounted using Vectashield (Vector Laboratories, Burlingame, CA).

Transplantations. Brains were dissected in ice-cold Krebs' buffer as described previously (Marin et al., 2000). Dlx1 $\leftrightarrow 2^{-1-}$ mutant and wildtype cells to be used for transplantation were removed and processed as described previously (Herrera et al., 1999).

\section{Results}

Dlx $1 \& 2^{-/-}$mutants lack olfactory bulb interneuron expression of Dlx5, GAD67, and Pax6

We previously demonstrated a severe reduction in the number of $\mathrm{OB} \mathrm{GABA}^{+}$and tyrosine hydroxylase (TH)-positive cells in E18.5 Dlx1 $2^{-/-}$mutants (Anderson et al., 1997b; Bulfone et al., 1998). Here we investigated the molecular features and mecha- nisms underlying this defect. We began by identifying global aspects of this phenotype using in situ RNA hybridization analysis of marker gene expression in sagittal sections at E14.5 and E18.5.

Expression of Dlx2,Dlx5, and GAD67 in the SVZ and mantle of E14.5 control embryos labels a rostral extension from the septum (Fig. $1 B, C, D$ ) and dorsal LGE (Long et al., 2003, their Fig. 5) into the early OB. In the $D l x 1 \& 2^{-/-}$mutants, expression of these genes does not extend into the OB (Fig. $\left.1 B^{\prime}, C^{\prime}, D^{\prime}\right)$. Dlx $1 \& 2^{-\prime}$ mutants express a truncated $D l \times 2$ transcript $(D l \times 2 m)$ in the LGE, MGE, and SE but not the OB (Fig. 1B') (Zerucha et al., 2000). The lack of $\mathrm{OB}$ expression of these molecular markers suggests that, from early embryonic stages, $D l x 1 \& 2^{-/-}$mutant OBs lack subpallial cells.

Expression of Pax6 marks at least three cell populations in and around the $\mathrm{OB}$ : VZ cells in the $\mathrm{OB}, \mathrm{OB}$ neurons, and scattered cells in the anterior olfactory nuclei (AON) (Stoykova and Gruss, 1994; Dellovade et al., 1998; Lopez-Mascaraque and de Castro, 2002; Hack et al., 2005; Kohwi et al., 2005). Among these Pax6 cells, the $D l x 1 \& 2^{-/-}$mutation appears to selectively eliminate the $\mathrm{OB}$ interneurons (Fig. $1 E^{\prime}$ ).

To examine the effect of the Dlx $\& 2^{-/-}$mutation on the development of pallial-derived projection neurons, we examined the expression of Reelin, whose expression in mitral cells is implicated as a detachment signal for migrating interneurons (Alcantara et al., 1998; Hack et al., 2002; Long et al., 2003). At E14.5, 


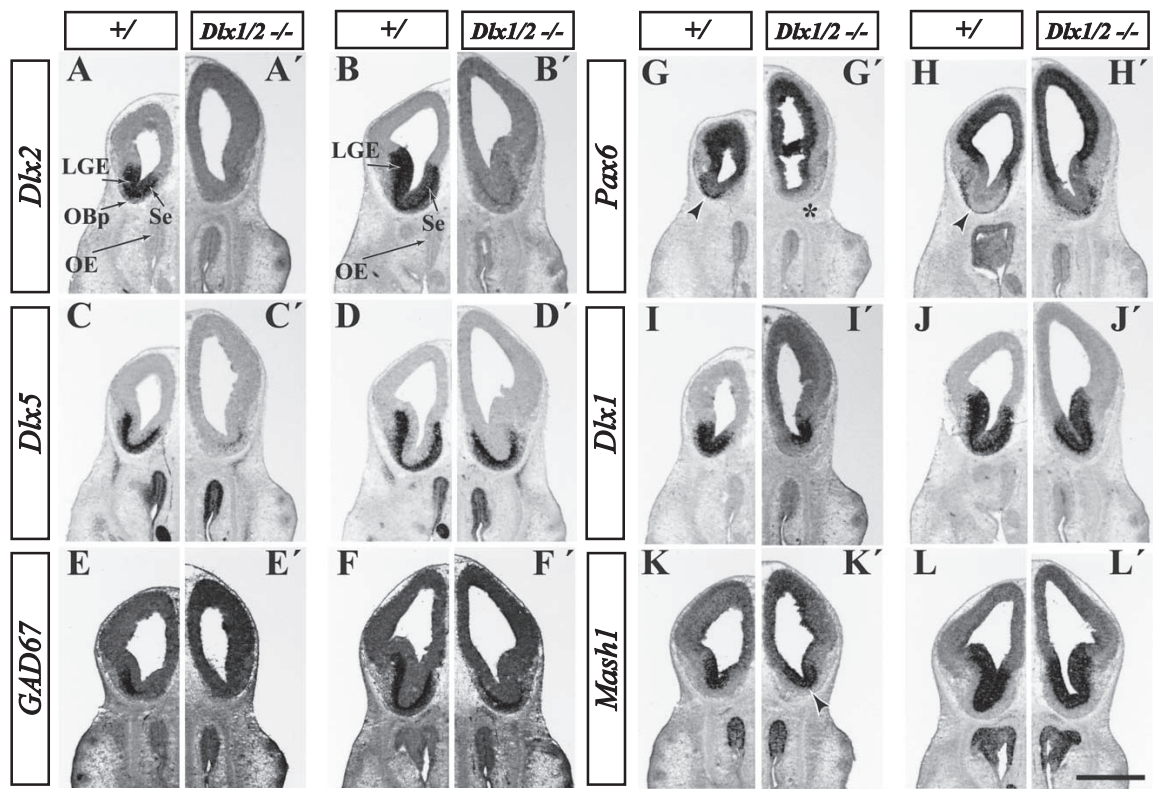

Figure 2. $\mathrm{E} 12.5 \mathrm{D} / \times 1 \& 2^{-/-}$mutant embryos show an early reduction of $\mathrm{OB}$ markers of differentiation despite maintenance of some early specification markers. Two coronal planes near the rostral pole of the telencephalon are shown. Hemisections (rostralmost in left panels) show nonradioactive in situ RNA hybridization analysis of $D / x 2$ in control $(\boldsymbol{A}, \boldsymbol{B})$ and $D / \times 1 \& 2^{-/-}$mutant $\left(\boldsymbol{A}^{\prime}\right.$, $\left.\boldsymbol{B}^{\prime}\right), D / x 5$ in control $(\boldsymbol{C}, \boldsymbol{D})$ and $D / x 1 \& 2^{-/-}$mutant $\left(\boldsymbol{C}^{\prime}, \boldsymbol{D}^{\prime}\right)$, GAD67 in control $(\boldsymbol{E}, \boldsymbol{F})$ and $D / x 1 \& 2^{-/-}$mutant $\left(\boldsymbol{E}^{\prime}, \boldsymbol{F}^{\prime}\right)$, and Pax6 in control $(\mathbf{G}, \boldsymbol{H})$ and $D / x 1 \& 2^{-/-}$mutant $\left(\boldsymbol{G}^{\prime}, \boldsymbol{H}^{\prime}\right)$ show a reduction in gene expression. $D / x 1$ in control $(\boldsymbol{I}, \boldsymbol{J})$ and $D / x 1 \& 2^{-/-}$mutant $\left(\boldsymbol{I}^{\prime}, \boldsymbol{J}^{\prime}\right)$ and Mash1 in control $(\boldsymbol{K}, \boldsymbol{L})$ and $D / x 1 \& 2^{-/-}$mutant $\left(\boldsymbol{K}^{\prime}, \boldsymbol{L}^{\prime}\right)$ embryos show maintenance of expression in the 0B primordium. Arrowhead in $\boldsymbol{I}^{\prime}$, Increased Mash1 expression in the SVZ; arrowhead in $\boldsymbol{K}, \boldsymbol{L}$, arch of Pax $\sigma^{+}$cells around rostral subpallium; star; loss of Pax6 expression in olfactory bulb primordium. OBp, Olfactory bulb primordium; OE, olfactory epithelium. Scale bar: $A-L^{\prime}, 1000 \mu \mathrm{m}$.

the $D l x 1 \& 2^{-/-}$mutation does not markedly affect expression of Reelin (Fig. $1 F^{\prime}$ ), further confirming that $\mathrm{OB}$ pallial cells are unaffected by this mutation (Bulfone et al., 1998).

By E18.5, immediately before the age at which the Dlx $1 \& 2^{-/-}$ mutants die, subpallial and pallial markers show similar expression patterns defects as at E14.5, thereby demonstrating that embryonic Dlx1 $\approx 2^{-1-}$ mutants lack normal OB GABAergic neurons from early stages. This phenotype could be attributable to either a defect in the specification of OB interneuron progenitors and/or a failure of these cells to differentiate and migrate. To gain additional insights into the basis of this phenotype, we performed in situ hybridization and immunofluorescence analyses on coronal sections at E12.5 and E15.5 (see Figs. 2-5).

\section{The $D l x 1 / 2^{-/-}$mutant OB lacks GABAergic differentiation yet} expresses transcription factors that mark subpallial progenitors To determine whether $D l x 1 \& 2$ participate in the initial specification of $\mathrm{OB}$ interneuron precursors, we examined the expression of transcription factors (Dlx1,2\&5, Mash1, and Pax6) and GAD67 in coronal sections through the rostral telencephalon in E12.5 embryos, around the time that a morphologically discernable OB is present directly above the olfactory epithelium.

At E12.5, Dlx2 is expressed in both immature and mature neurons of the LGE, septum, and OB (Fig. $2 A, B$ ). Expression of the $D l \times 2$ truncated RNA $(D l \times 2 m)$ in the $D l \times 1 \& 2^{-/-}$mutant is maintained in the SVZ of the septum and LGE but is barely detectable in the OB, similar to the results at E14.5 (Figs. $1 B^{\prime}$, $\left.2 A^{\prime}, B^{\prime}\right)$.

Dlx5 is expressed in the SVZ and mantle zone of the LGE, septum, and $\mathrm{OB}$ in the control embryos (Fig. 2C,D). Its expression is virtually eliminated in the $D l \times 1 \& 2^{-/-}$mutant telencephalon, except in the septum and rostral LGE (Anderson et al., 1997b). At E12.5, the Dlx1\& $2^{-/-}$mutant OB primordium has trace levels of $D l \times 5$ expression (Fig. 2C').

GAD67 expression is similar to $D l x 5$ expression in the LGE, septum, and OB at E12.5 (Fig. 2E,F). However, in the Dlx $\& 2^{-/-}$mutant, GAD67 expression is lost from the $\mathrm{OB}$ and reduced in the LGE and septum (Fig. $2 E^{\prime}, F^{\prime}$ ). The observation that $D l \times 5$ and GAD67 expression remains prominent in part of the septum and rostral LGE in the Dlx1\&2 $2^{-/-}$mutant suggests that the genesis of GABAergic neurons in the $\mathrm{OB}$ and the septum/rostral LGE are under distinct molecular controls.

Pax6 is expressed in radial cohorts of cells at the pallial-subpallial border, at both the LGE/ventral pallial (VP) and septal/medial pallial (MP) limits (Puelles et al., 2000; Yun et al., 2003). At E12.5, these cells form a continuous arc around the rostral subpallium and cap the primordium of the OB (Fig. 2G,H, arrowheads). In the Dlx $\& 2^{-1-}$ mutant, production of the $\mathrm{Pax}^{+}$cells is intact (they form the subpallial arc), but they aggregate in clusters and are not detected in the $\mathrm{OB}$ primordium (Figs. $2 G^{\prime}, H^{\prime}$, star; $3 A A^{\prime}, B$ $B^{\prime}, C C^{\prime}$, E15.5 data).

A truncated $D l \times 1$ transcript $(D l \times 1 m)$ is expressed in both progenitors and more mature cells of the LGE, septum, and OB of E12.5 control embryos (Fig. $2 I, J)$. In the basal ganglia primordia of the Dlx $\& 2^{-1-}$ mutants, expression of Dlx $1 m$ is maintained (Fig. $2 I^{\prime}, J^{\prime}$ ) (Zerucha et al., 2000). In the E12.5 Dl $\times 1 / 2^{-/-}$mutant, Dlx $1 \mathrm{~m}$ is expressed in the OB primordium in the VZ (immature progenitors), whereas its expression in the mantle zone (more mature cells) is not detectable (Fig. $\left.2 I^{\prime}, J^{\prime}\right)$.

Mash1 encodes a basic helix-loop-helix transcription factor that promotes development of OB GABAergic neurons (Casarosa et al., 1999; Parras et al., 2004). Dlx $\& 2^{-/-}$mutants overexpress Mash1 in the ganglionic eminences; this is associated with increased Delta1 and Hes5 expression, indicative of increased Notch signaling (Yun et al., 2002). At E12.5, Mash1 continues to be expressed in the mutant OB (Fig. $2 K^{\prime}, L^{\prime}$ ). This demonstrates that the $\mathrm{OB}$ progenitor domain maintains expression of some essential regulatory genes in the $D l x 1 \& 2^{-/-}$mutant.

Thus, early aspects of $\mathrm{OB}$ interneuron specification take place in Dlx \& $2^{-/-}$mutants, but later steps in their generation fail. We investigated this hypothesis further at E15.5, when the olfactory bulb has differentiating granule and periglomerular interneurons that express several transcription factors ( $D l x 1, E R 81, P a x 6, S p 8$, and $S p 9$ ) and other genes (GAD67 and $P K 2)$ that regulate their phenotype.

\section{Evidence for Dlx $\& 2$-dependent and -independent} mechanisms in the genesis of olfactory bulb interneurons At E15.5, Dlx1 expression marks both immature and mature neurons in the wild-type forebrain. Its expression in the subventricular and mantle zones of the subpallium extends rostrally from the LGE into the olfactory bulb in a U-shaped pattern (Fig. 3A-F, arrowheads), which becomes a ventrolateral crescent in the VZ/ 

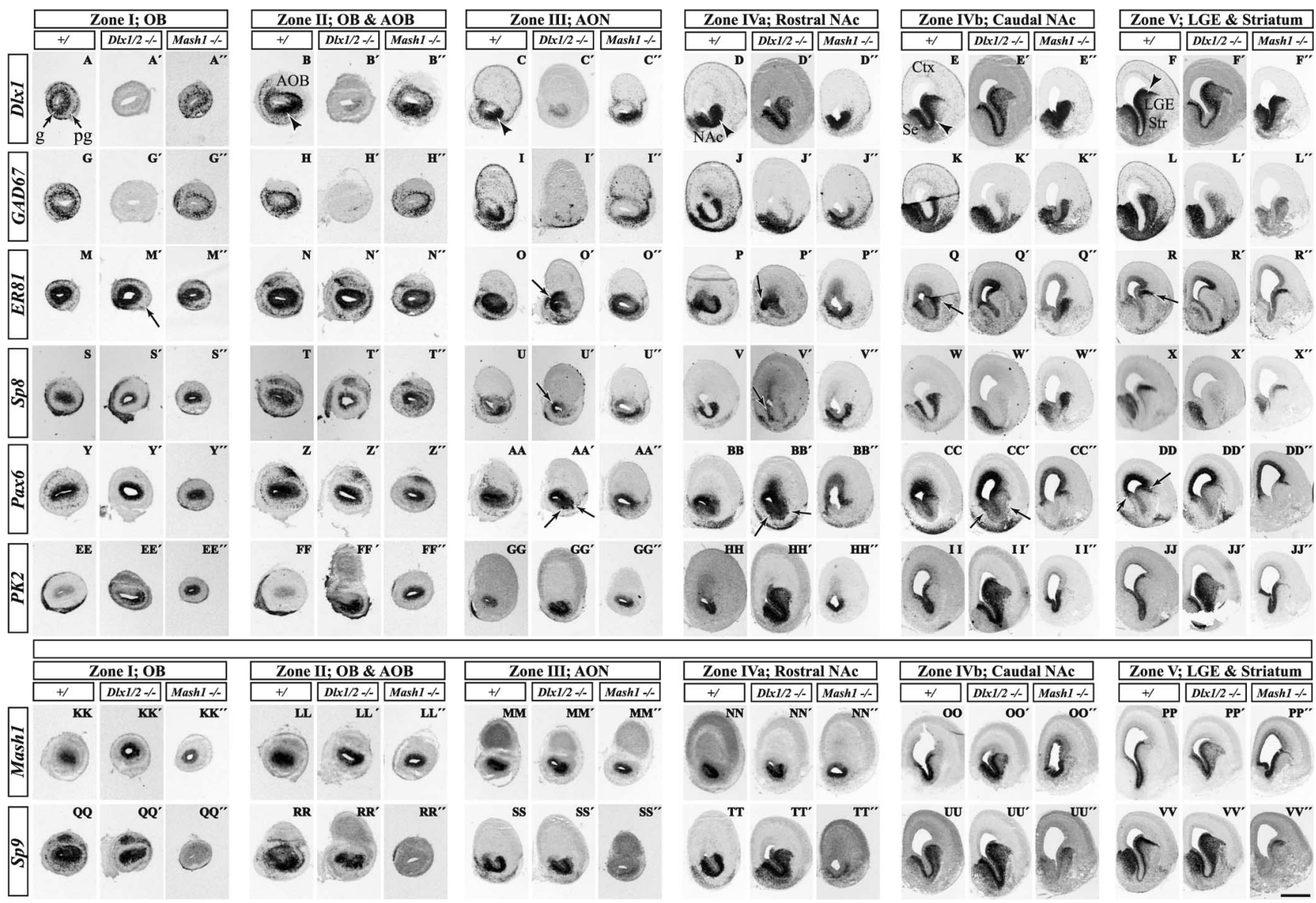

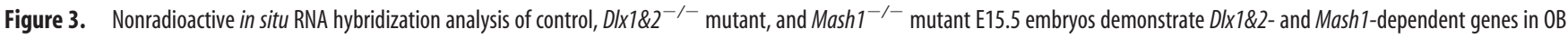
development. Six coronal planes of the rostral telencephalon are shown; we conceptually organized the six planes into five zones (I-V) shown in Figure $1 F$ (for an explanation of the five zones, see Results and Fig. 9; we subdivided zone IV into IVa and IVb). Hemisections show the expression of various genes in three types of mice: control (left column), Dlx $1 \& 2^{-/-}$mutant (middle column), and $M a s h 1^{-1-}$ mutant (right column) for each telencephalic zone. In general, the Mash $1^{-1-}$ mutation shows the opposite effect of the $D / x 1 \& 2^{-/-}$mutation. The following genes show decreased

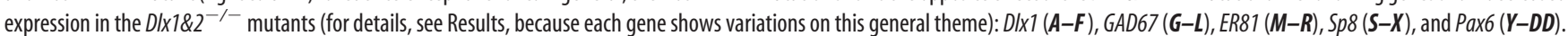

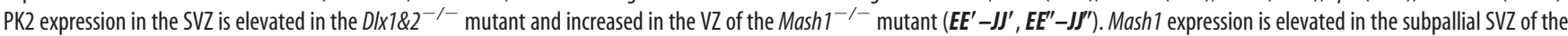

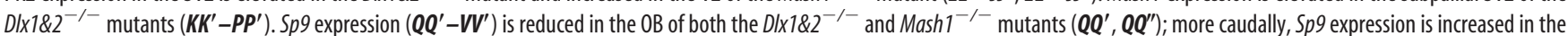
$D \mid x 1 \& 2^{-1-}$ mutants and decreased in the Mash $1^{-1-}$ mutants $\left(\boldsymbol{T}^{\prime}-\boldsymbol{V}^{\prime}, \boldsymbol{T}^{\prime \prime}-\boldsymbol{V}^{\prime \prime}\right)$. g, Granule cell layer; pg, periglomerular cell layer; Str, striatum. Scale bar: $\boldsymbol{A}-\boldsymbol{B}^{\prime \prime}, \mathbf{G}-\boldsymbol{H}^{\prime \prime}, \boldsymbol{M}-\boldsymbol{N}^{\prime \prime}, \mathbf{S}-\boldsymbol{T}^{\prime \prime}, \boldsymbol{V}-\boldsymbol{Z}^{\prime \prime}$, $E E-F F^{\prime \prime}, K K-L L^{\prime \prime}, Q Q-R R^{\prime \prime}, 1000 \mu \mathrm{m} ; C_{-} C^{\prime \prime}, I-I^{\prime \prime}, 0-O^{\prime \prime}, U-U^{\prime \prime}, A A-A A^{\prime \prime}, G G-H H^{\prime \prime}, M M-N N^{\prime \prime}, S S-I T^{\prime \prime}, 750 \mu \mathrm{m} ; D-F^{\prime \prime}, J-L^{\prime \prime}, P-R^{\prime \prime}, V-X^{\prime \prime}, B B-D D^{\prime \prime}, I I-J J^{\prime \prime}, 00-P P^{\prime \prime}, U U-V V^{\prime \prime}, 500 \mu \mathrm{m}$.

SVZ of the OB (Fig. $3 B, C$, arrowheads). The U-shaped domain can be seen at E12.5 (Fig. $2 \mathrm{~A}$ ) and is complementary to an inverted U-shape domain (data not shown). The U-shaped progenitor domain has subpallial molecular features (Dlxl,2\&5 and Sp8) (see Figs. 2-4, 9), whereas the inverted U-shaped progenitor domain primarily has pallial molecular features ( $\mathrm{Tbr} 2$; data not shown). There are some genes that are expressed in both the pallial and subpallial progenitor domains [ER81, Emx] (empty spiracles homolog 1) Mash1, Pax6, and Sp8, although at different levels] (see Figs. 3, 4, 9 and data not shown). Dlxl is expressed in nascent granule and periglomerular layers (Fig. $3 A$ ). In the $D l x 1 \& 2^{-1-}$ mutant, the Dlxl transcript continues to be expressed in the SVZ of the subpallium; although low levels are seen in the U-shaped zone, no expression is observed in the $\mathrm{OB}$ (Fig. $3 A^{\prime}-C^{\prime}$ ).

Emxl is expressed in both the $\mathrm{U}$-shaped and inverted U-shaped domain; in the Dlxl $\& 2^{-/-}$mutant, expression in only the U-shaped domain is reduced (data not shown). This suggests that a subset of immature olfactory bulb interneurons express Emxl, consistent with fate mapping studies (Gorski et al., 2002) (M. Kohwi et al., unpublished observations).

GAD67 expression in control embryos is very similar to $D l x 1$ (although GAD67 is expressed more robustly in the mantle zone) (Fig. 3G-L). Like Dlx1 expression in the Dlxle $2^{-/-}$mutants, GAD67 expression is lost in the OB (Fig. 3G'). Its expression is reduced in the LGE but appears normal in the septum (Fig. $3 J^{\prime}-$ $\left.L^{\prime}\right)$. Septal development is relatively normal in the Dlxl $\dot{\sim} 2^{-\prime-}$ mutant, which we believe is attributable to preservation of $D l x 5 \ll 6$ expression by a $D l x 1 \& 2$-independent pathway (Anderson et al., 1997b).

Expression of ER81, an ETS-domain transcription factor, in the rostral dLGE and dorsal septum marks sets of cells ventral to the radial stripes of $\mathrm{Pax6}^{+}$cells (Fig. $3 Q, R, C C, D D$, arrows) (Stenman et al., 2003). These ER81 expression domains coalesce into the U-shaped rostral subpallial domain (like Dlxl and GAD67) and then form rings of expression in the mantle and SVZ of the OB (Fig. 3M-R). In the Dlx $1 \ll 2^{-/-}$mutant, ER81 expression is lost from the dLGE and the U-shaped domain (Fig. $\left.3 M^{\prime}-R^{\prime}\right)$. However, similar to $D l x 1$ and GAD67, ER81 expression remains in the septum (Fig. $\left.3 Q^{\prime}, R^{\prime}\right)$. Furthermore, ER81 is expressed in the $\mathrm{VZ}$ of the rostromedial pallium, which is continuous with the inverted $\mathrm{U}$ domain; this expression is preserved in the $D l \times 1 / 2^{-/-}$mutant (Fig. $3 O^{\prime}, P^{\prime}$, arrows). Furthermore, many 
$E R 81^{+}$cells remain in the mutant $\mathrm{OB}$ mantle zone, although there is reduced expression in the ventral region (Fig. $3 M^{\prime}$, arrow). We hypothesize that the remaining $E R 81^{+}$mantle zone cells are derived from the $E R 81^{+}$progenitors in the inverted $\mathrm{U}$ domain.

Sp8 encodes a buttonhead-like $\mathrm{C}_{2} \mathrm{H}_{2}$ zinc-finger transcription factor that regulates development of olfactory bulb interneurons (Waclaw et al., 2006). Sp8 and ER81 expression are very similar (Fig. $3 M-R, S-X)$. In the $D l x 1 \& 2^{-1-}$ mutant, $S p 8$ expression in the dLGE, U-shaped domain, and OB mantle zone is virtually eliminated (Fig. $3 S^{\prime}-X^{\prime}$ ). Sp8 expression persists in the septal mantle zone (MZ) (but is reduced in the septal VZ) (Fig. $3 X^{\prime}$ ). Like ER81, $S p 8$ is also expressed in the inverted $U$ domain and in the $\mathrm{VZ}$ of the OB. This expression persists in the Dlx1 $\mathrm{e} 2^{-1-}$ mutant (Fig. $3 U^{\prime}, V^{\prime}$, arrows).

Pax6 is expressed in cells radially migrating out as thin radial cohorts at the pallial-subpallial border at both the LGE/ventral pallial and septal/medial pallial limits (Fig. 3DD, arrows) (Puelles et al., 2000; Yun et al., 2003). These appear to be continuous into the $\mathrm{OB}$, in which there are $\mathrm{Pax} 6^{+} \mathrm{PG}$ cells. Pax 6 expression is lost in PG cells of the Dlx $\& 2^{-/-}$mutant (Fig. $3 Y^{\prime}$ ). Of note, clumps of $\mathrm{Pax}^{+}$cells in the SVZ of the rostral subpallium are observed

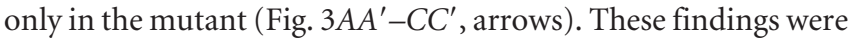
confirmed and analyzed in greater depth using immunohistochemistry (described below and in Fig. 4).

$P K 2$ encodes a secreted, postulated detachment signal for migrating neurons of the postnatal RMS (Ng et al., 2005). PK2 expression in the VZ/SVZ extends from the basal ganglia primordia into the $\mathrm{U}$-shaped region with low levels in the OB. Its expression is increased in the SVZ of the Dlx $1 \ll 2^{-/-}$mutants (Fig. $3 E E^{\prime}-J J^{\prime}$ ).

Mash1 is expressed in the VZ and SVZ of the subpallium and $\mathrm{OB}$ (Fig. $3 K K-P P$ ). Similar to PK2, Mash1 expression is increased in the SVZ of the LGE and the U-shaped domain in the $D l x 1 \& 2^{-/-}$mutants, although its expression appears unchanged in the $\mathrm{OB}$ (Fig. $3 K K^{\prime}-P P^{\prime}$ ).

Sp9 encodes a buttonhead-like $\mathrm{C}_{2} \mathrm{H}_{2}$ zinc-finger transcription factor highly related to $S p 8$. Expression of $S p 9$ in the subpallium and $\mathrm{OB}$ is very similar to $D l x 1$ and $G A D 67$ (Fig. $3 A-F, G-L$ ). Like Mash1, Sp9 expression is increased in the dLGE and U-shaped domain in the Dlxl\& $2^{-/-}$subpallial SVZ/VZ (Fig. 3QQ $Q^{\prime}-V V^{\prime}$ ); In the OB, $S p 9$ expression is maintained in the VZ but is greatly reduced in the granule and periglomerular layers (Fig. 3QQ').

Therefore, there appears to be two types of gene expression responses to the $D l x 1 \& 2^{-/-}$mutation in progenitor domains that are involved in the generation of olfactory bulb neurons: (1) downregulation of Dlx5, ER81, GAD67, and $S p 8$, and (2) maintenance/upregulation of Mash1, Sp9, and PK2. This suggests that $D l x 1 \& 2$ and Mash 1 regulate distinct pathways. To test this, we examined the effect of the Mash $1^{-/-}$mutant on the expression of these genes.

\section{Mash1 promotes expression of $S p 9$}

We studied the expression of Dlx1, GAD67, ER81, Sp8, Pax6, Sp9, and PK2 in coronal sections of E15.5 Mash1 ${ }^{-1-}$ mutants. Contrary to the effects in the Dlx1 $\mathrm{e} 2^{-1-}$ mutant, GAD67 expression is maintained in most of the Mash $1^{-/-}$subpallium (Fig. $3 G^{\prime \prime}-L^{\prime \prime}$ ), as is Dlxl expression (Fig. $\left.3 A^{\prime \prime}-F^{\prime \prime}\right)$. At earlier stages (E10.5E12.5), Dlx1,2@5 and GAD67 expression are ectopically expressed in the VZ in the Mash1 $1^{-/-}$mutants (Casarosa et al., 1999; Yun et al., 2002). In the OB, Dlx1 and GAD67 expression are maintained in the granule cell layer but appear to be reduced the periglomerular layer (Fig. $3 A^{\prime \prime}, G^{\prime \prime}$ ). Likewise, expression of ER81 and $S p 8$ is maintained in the dLGE, $\mathrm{U}$-shaped domain, and $\mathrm{OB}$ of the Mash $1^{-/-}$mutant (Fig. $3 M^{\prime \prime}-R^{\prime \prime}, S^{\prime \prime}-X^{\prime \prime}$ ). PK2 expression in the
$\mathrm{VZ}$ of the $\mathrm{OB}$ is increased in the $\mathrm{Mash}^{-/-}$mutant (Fig. $\left.3 E E^{\prime \prime}, F F^{\prime \prime}\right)$. This suggests that Mash1 represses $P K 2$ expression in $\mathrm{OB}$ progenitors.

Unlike Dlx1, GAD67, ER81, and Pax6, the expression of $S p 9$ is reduced in $M a s h 1^{-1-}$ mutants in regions of the subpallium. Sp9 expression is reduced in the VZ, SVZ, and MZ of ventral parts of the LGE, the U-shaped region and the septum (Fig. 3QQ $\left.Q^{\prime \prime}-V V^{\prime \prime}\right)$. However, its expression is maintained in the dLGE (Fig. $3 V V^{\prime \prime}$ ). OB expression of $S p 9$ is greatly reduced (Fig. $3 Q Q^{\prime \prime}$ ).

Thus, in most subpallial domains, $D l \times 1 \& 2$ positively regulates GAD67, ER81, and Sp8 and negatively regulates Mash1, Sp9, and $P K 2$. Conversely, in most subpallial domains, Mash1 positively regulates $S p 9$ and negatively regulates $D l x 1, G A D 67$, and ER81. Because Dlx1\&2 and Mash1 are both required for the normal generation of $\mathrm{OB}$ interneurons, this suggests that these transcription factors regulate parallel genetic pathways that together are essential for OB development.

Interestingly, Pax6 expression in the subpallium does not seem to be greatly affected by either the $D l x 1 \& 2$ or Mash 1 mutation, with the exception of decreased numbers of Pax $6^{+} \mathrm{OB}$ cells in the mantle zone of both mutants (Fig. $3 Y^{\prime}, Y^{\prime \prime}$ ). However, there are clumps of $\mathrm{Pax}^{+}$cells in the SVZ of the rostral subpallium in the Dlx $1 \& 2^{-1-}$ mutant. Thus, we chose to examine the relationship of DLX2 and PAX6 protein expression at higher resolution.

\section{Molecular profile of E15.5 progenitor zones related to the genesis of olfactory bulb interneurons: expression of DLX2 and PAX6 proteins}

We examined expression of PAX6 and DLX2 proteins using double immunofluorescence at E15.5 in rostral telencephalic regions related to the genesis of olfactory bulb interneurons. We will describe the results in four coronal section planes of the rostral telencephalon that are representative of the regions related to the genesis of olfactory bulb interneurons. We name these planes as follows: zone I, OB; zone II, accessory olfactory bulb (AOB); zone III, AON; and zone IV, rostral nucleus accumbens (NAc). Later in the paper we introduce the idea of zone $\mathrm{V}$, which includes the LGE/striatum and more posterior parts of the NAc. Figure 4 shows double immunofluorescence (for a schematic interpretation of this data, see Fig. 9). We qualitatively categorized cells as follows: strongly DLX2 positive $\left(\mathrm{DLX} 2^{+}\right)$, strongly PAX6 positive $\left(\mathrm{PAX}^{+\mathrm{s}}\right)$, weakly PAX6 positive $\left(\mathrm{PAX}^{+\mathrm{w}}\right), \mathrm{DLX}^{+} /$ $\mathrm{PAX}^{+\mathrm{s}}$ double positive, and DLX2 ${ }^{+} / \mathrm{PAX}^{+\mathrm{w}}$ double positive. Below we highlight a subset of the major observations, focusing on the expression related to the genesis of OB interneurons, such as the rostral parts of the pallial/subpallial boundary, in which at least some of the embryonic olfactory bulb interneurons are thought to be generated.

\section{General observations about proliferative and differentiating layers (Fig. 4) \\ $V Z$}

PAX6 is strongly expressed in the pallial VZ and weaker in the subpallial (LGE and septal) VZ, in a pattern similar to its RNA expression (Fig. 3Y-DD) (Sussel et al., 1999; Puelles et al., 2000). In the pallial VZ, most cells are $\mathrm{PAX}^{+\mathrm{s}}$, and there are scattered $\mathrm{DLX}^{+}$cells that appear to be PAX6 negative $\left(\mathrm{PAX}^{-}\right)$. In the subpallial LGE-related VZ, most cells are PAX6 ${ }^{+\mathrm{w}}$ (note that cells of the MGE are PAX6 ${ }^{-}$); in addition, there are large numbers of $\mathrm{DLX}_{2}{ }^{+}$cells that coexpress PAX6 (these are PAX6 ${ }^{+\mathrm{w}}$ cells).

\section{$S V Z$}

PAX6 is weakly expressed in the both the pallial and subpallial SVZ. DLX2 is strongly expressed in the subpallial SVZ, in which it 


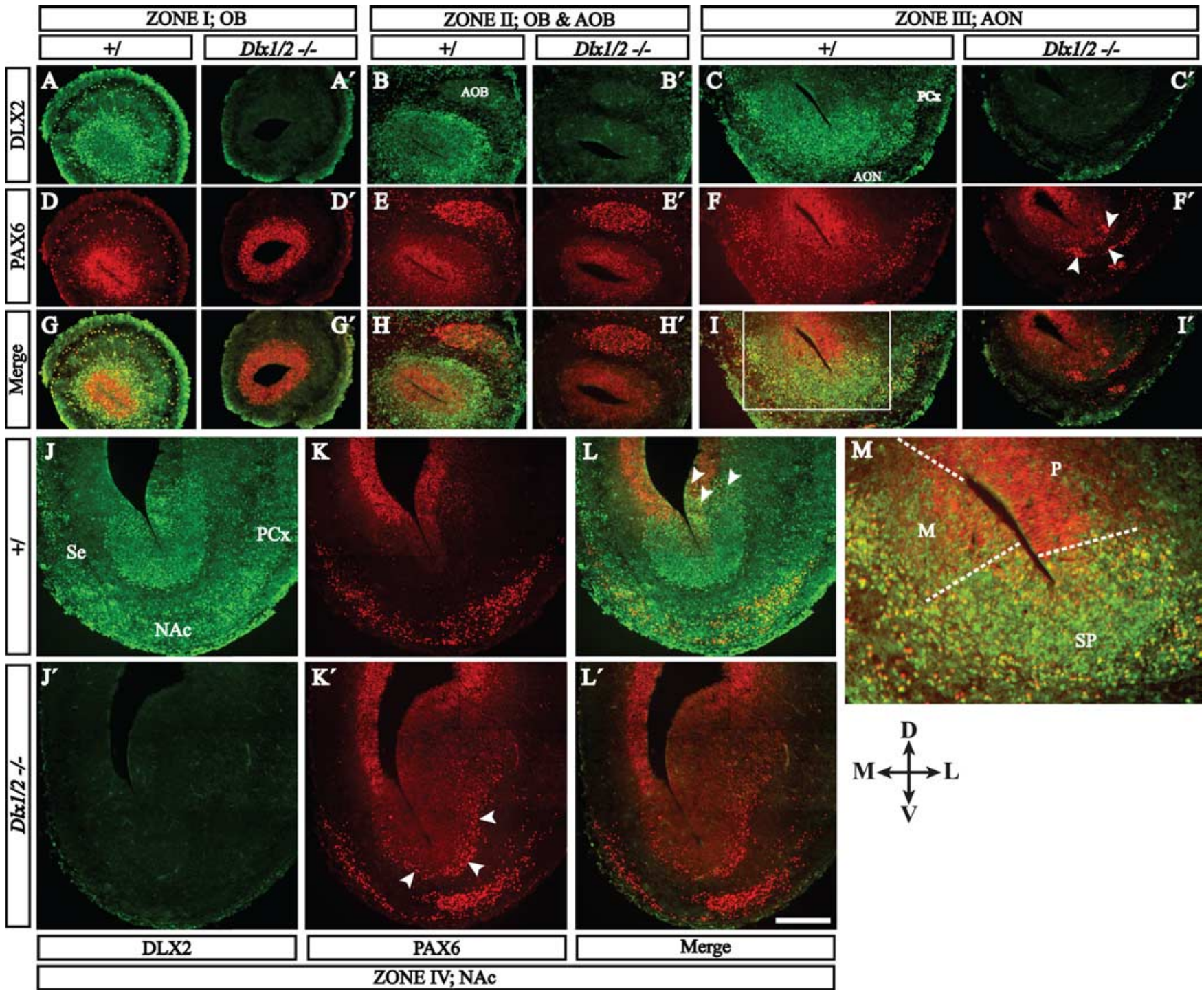

Figure 4. PAX6 (red immunofluorescence) and DLX2 (green immunofluorescence) protein expression define zones and cell types related to the E15.5 olfactory bulb. Four coronal planes of the rostral telencephalon are shown; we conceptually organized these four planes into five zones (I-IV) shown in Figure $1 F$ (for an explanation of these zones, see the Results and Fig. 9). In each zone,

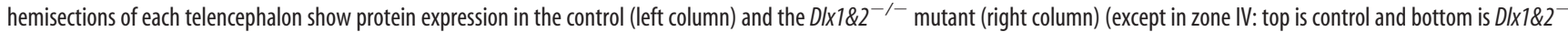
mutant). $M$ is a higher-magnification view of the boxed region of zone III (I), showing the approximate boundaries between the pallial (P), mixed (M), and subpallial (SP) progenitor domains. Arrowheads in $\boldsymbol{F}^{\prime}$ and $\boldsymbol{K}^{\prime}$ show ectopic clusters of PAX6 ${ }^{+}$cells in the $D / x 1 \& 2^{-1-}$ mutant. Scale bar: $\boldsymbol{A}-\boldsymbol{L}^{\prime}, 250 \mu \mathrm{m} ; \boldsymbol{M}, 100 \mu \mathrm{m}$. PCX, Piriform cortex; $\mathrm{D}$, dorsal, L, lateral; $M$, medial; $V$, ventral.

is probably coexpressed with PAX6. DLX2 is expressed in scattered cells in the pallial SVZ; these cells appear not to express PAX6.

\section{$M Z$}

PAX6 is strongly expressed in scattered subpallial cells but not pallial ones. Some of these subpallial cells coexpress DLX2, which is widely expressed in the subpallium. However, most of these cells are PAX6 ${ }^{-}$. DLX2 ${ }^{+}$pallial cells are PAX6 ${ }^{-}$.

Zone IV: rostral NAc (Fig. 4J-L) (see Fig. 9D)

$V Z / S V Z$. In the dLGE/VP pallial/subpallial transition zone, there are numerous DLX2 ${ }^{+} / \mathrm{PAX}^{+s}$ double-positive cells in the VZ and SVZ (Fig. 4L, arrowheads). Conversely, the dorsal septum/MP pallial/subpallial transition zone has many fewer DLX $2^{+} / \mathrm{PAX}^{+\mathrm{s}}$ double-positive cells.

$M Z$. Emanating from the dLGE/VP pallial/subpallial transition zone is a stream of $\mathrm{DLX} 2^{+} / \mathrm{PAX}^{+s}, \mathrm{PAX}^{+\mathrm{s}}{ }^{\text {, and } \mathrm{DLX} 2^{+}}$ cells (Fig. $4 L$ ). The septum/MP boundary produces a smaller stream of cells; these are primarily either PAX $6^{+s}$ or DLX2 ${ }^{+}$, and very few are DLX $2^{+} / \mathrm{PAX}^{+\mathrm{s}}$.

In the Dlxl\&2 $2^{-1-}$ mutant, there are ectopically placed PAX6 ${ }^{+s}$ cells that collect at SVZ/MZ transition in the subpallium (Fig. $4 K^{\prime}$, arrowheads).

\section{Zone III: AON (Figs. 4C,F,I) (see Fig. 9C)}

The principal changes compared with the dLGE/septal level are as follows.

$V Z / S V Z$. Increased numbers of pallial $\mathrm{DLX}^{+}{ }^{+}$on the medial (septal/MP) side and an increase in DLX $2^{+} / \mathrm{PAX}^{+\mathrm{s}}{ }^{\text {cells present }}$ in the subpallial (U-shaped) domain.

$M Z$. Robust streams of PAX6 ${ }^{+s}$ emanate from the lateral and medial pallial/subpallial boundary. These streams are continuous with a superficial layer of PAX6 ${ }^{+\mathrm{s}}$ cells that wrap around the ventral surface of the brain.

In the Dlx1 $\mho 2^{-/-}$mutant embryo, there are many clusters of $\mathrm{PAX}^{+}{ }^{+}$cells along the arc of the rostral subpallium and just 
inside the SVZ of the dLGE/VP and septum/MP borders (Fig. $4 F^{\prime}$, arrowheads).

Zone II: $\mathrm{OB}$ and $\mathrm{AOB}$ (Fig. 4B,E,H) (see Fig. 9B)

The principal changes compared with the AON level are as follows.

$V Z$. The size of the subpallial (U-shaped) domain is reduced; most of the VZ is $\mathrm{PAX6}^{+\mathrm{s}}$, although PAX6 expression remains stronger on the dorsolateral side. There are scattered DLX2 ${ }^{+}$cells and very few DLX $2^{+} / \mathrm{PAX}^{+\mathrm{s}}$ cells.

SVZ. The SVZ is a mixture of DLX2 ${ }^{+}$and PAX $6^{+\mathrm{w}}$ cells; there are a few scattered PAX ${ }^{+s}$ cells; DLX2 ${ }^{+} /$PAX $^{+s}$ cells are concentrated in the small subpallial (U-shaped) domain.

$M Z$. A zone dominated by DLX2 ${ }^{+}$cells begins to encircle the progenitor domains. It contains scattered $\mathrm{DLX} 2^{+} / \mathrm{PAX} 6^{+s}$ cells and very few $\mathrm{PAX}^{+\mathrm{s}}$.

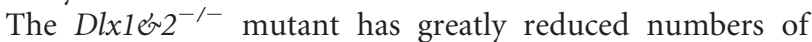
PAX6 $^{+}$cells emanating from the subpallial domain (Fig. $4 E^{\prime}$ ).

Zone I: OB (Fig. 4A,D,G) (see Fig. 9A)

The principal changes compared with the $\mathrm{AOB}$ level are as follows.

$V Z$. There is no detectable subpallial (U-shaped) domain, and there are more $\mathrm{DLX} 2^{+} / \mathrm{PAX} 6^{+\mathrm{s}}$ cells.

SVZ. The SVZ is a mixture of DLX2 ${ }^{+}, \mathrm{PAX}^{+\mathrm{w}}, \mathrm{PAX}^{+\mathrm{s}}$, and DLX $2^{+} / \mathrm{PAX}^{+\mathrm{s}}$ cells that circumscribe the VZ.

$M Z$. Granule and periglomerular layers circumscribe the progenitor layers and contain a mixture of $\mathrm{DLX} 2^{+}, \mathrm{PAX}^{+\mathrm{s}}{ }^{\text {, }}$, and $\mathrm{DLX}^{+} / \mathrm{PAX}^{+\mathrm{s}}$ cells.

The Dlxl\& $2^{-1-}$ mutants lack PAX6 ${ }^{+}$cells in the granule or periglomerular layers (Fig. $4 D^{\prime}$ ).

This detailed analysis shows, at the cellular resolution, the modifications in the molecular characteristics of the progenitor domains as one moves rostrally from the level of the NAc/rostral LGE (zone IV) to the OB (zone I). In this rostral progression, there is a loss in regional differences of molecular properties. In the OB, the VZ/SVZ shows no clear regional difference in gene expression; its molecular features are a mosaic of the pallium and subpallium.

The pallial/subpallial boundaries (dLGE/VP and dorsal septum/MP) are present in zones III-V, in which they appear to be the source for migratory PAX6 ${ }^{+}$cells. These boundaries are not apparent in the OB. The Dlxl\& $2^{-/-}$mutants do not show a major change in the VZ/SVZ expression of PAX6 (Fig. $4 D^{\prime}-$ $\left.F^{\prime}, K^{\prime}\right)$. However, $\mathrm{PAX}^{+}$cells that have left the VZ/SVZ are found in ectopic clusters in zones III and IV, suggestive of a defect in migration (similar clusters are present in Figs. $2 H^{\prime}, 3 A A^{\prime}-$ $\left.C C^{\prime}\right)$. Furthermore, given the known functions for $D l x 1 \nLeftarrow 2$ in regulating the migration of MGE-derived interneurons (Anderson et al., 1997a, 2001) and the lack of $D l x 1^{+}$and $D l x 2^{+}$cells in the OB of the Dlx $1 \mathrm{e} 2^{-/-}$OB (Figs. $1 B^{\prime}, H^{\prime}, 2 A^{\prime}, I^{\prime}, 3 A^{\prime}$ ), we directly examined the migratory properties of Dlx $1 \mathrm{\&} 2^{-/-}$cells in the embryonic rostral migratory stream and of dLGE cells.

\section{In vitro analyses reveal a rostral migratory stream defect in the Dlx 1 \& $2^{-/-}$mutant embryos}

To determine whether a block in migration along the rostral migratory stream contributes to the lack of $\mathrm{OB}$ interneuron neuron marker expression in the Dlx $1 \hookleftarrow 2^{-/-}$mutant embryo, we used an in vitro slice culture migration assay using parasagittal vibrating microtome slices from E17.5 control and Dlx1\&2-/mutant embryos. The RMS was labeled with a crystal of DiI, and slices were cultured for $72 \mathrm{~h}$. The experiment indicated a reduced
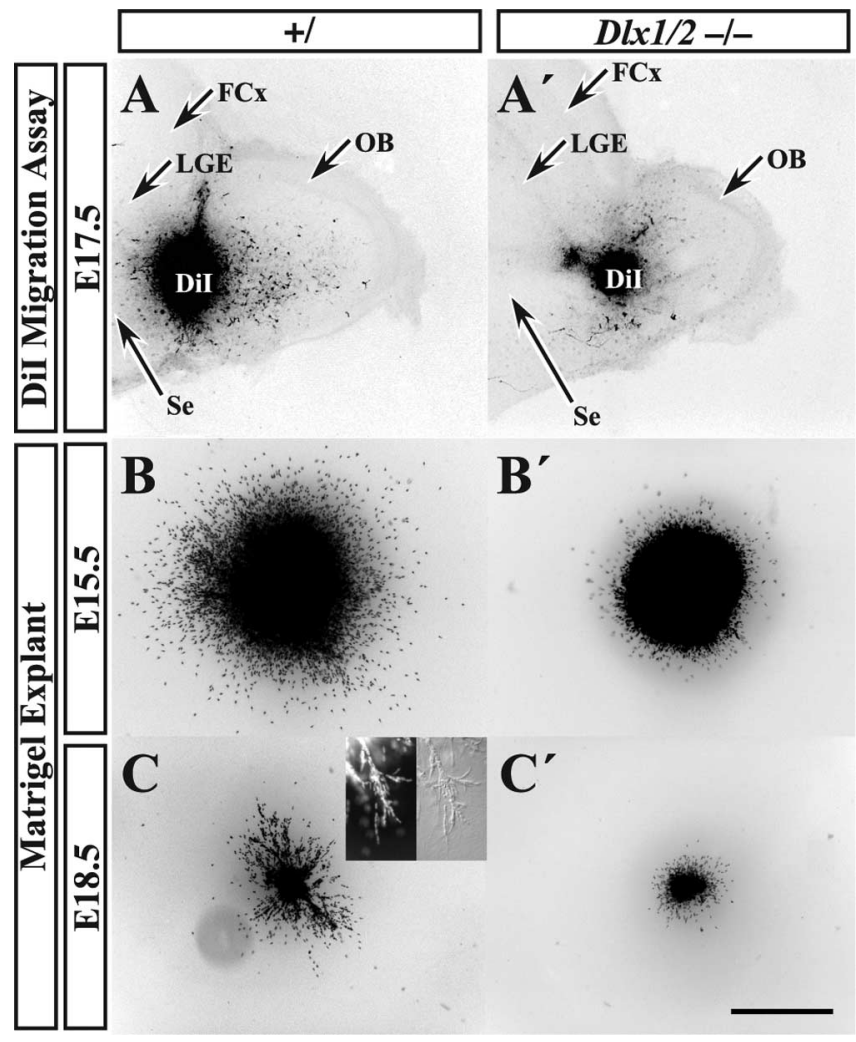

$\mathbf{B}^{\prime}$

Figure 5. In vitro migration analysis of $D / x 1 \& 2^{-/-}$mutant embryos reveals reduced migratory capacity of the RMS. A Dil crystal was placed into the RMS of E17.5 D/x $1 \& 2^{-/-}$mutant $\left(\boldsymbol{A}^{\prime}\right)$ and control $(\boldsymbol{A})$ embryos, and the sections were allowed to survive for $72 \mathrm{~h}$. Immunofluorescence analysis (converted to black and white) shows that $D / x 1 \& 2^{-/-}$mutants have greatly reduced numbers of labeled cells migrating into the $O B\left(\boldsymbol{A}^{\prime}\right)$. Small explants of approximately the same size of SVZ cells taken from the LGE of $D\left(x 1 \& 2^{-/-}\right.$mutant and control embryos were

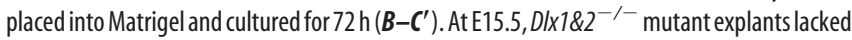
migration of Hoechst-stained cells away from the explant when compared with controls $\left(\boldsymbol{C}, \boldsymbol{C}^{\prime}\right)$. At E18.5, not only were the $D / x 1 \& 2^{-1-}$ mutant cells unable to migrate away from the explant $\left(\boldsymbol{D}, \boldsymbol{D}^{\prime}\right)$, but they were also unable to form chains similar to controls (inset in $\left.\boldsymbol{D}\right)$. $F(x$, Frontal cortex.. Scale bar: $\boldsymbol{A}, \boldsymbol{A}^{\prime}, 450 \mu \mathrm{m} ; \boldsymbol{B}^{\prime} \boldsymbol{B}^{\prime}, 100 \mu \mathrm{m} ; \boldsymbol{C}^{\prime} \boldsymbol{C}^{\prime}, 350 \mu \mathrm{m}$; inset, $50 \mu \mathrm{m}$.

migration along the rostral migratory stream into the $\mathrm{OB}$ in the Dlxl\& $2^{-/-}$mutant embryos $(n=5)$ compared with control $(n=$ 8) (Fig. $5 A, A^{\prime}$ ).

The results obtained using the slice migration assay support a hypothesis that tangential migration in the RMS is defective in the Dlx $1 \& 2^{-\prime-}$ mutants. This abnormality could be attributable to local defects along the migration pathway or to intrinsic defects in the migrating cells. Therefore, to assess whether or not $D l x 1 \leftrightarrow 2^{-/-}$cells could migrate in other environments, we tested the ability of explants from the rostral parts of the dLGE to undergo chain migration in Matrigel. Explants from the RMS exhibit chains of migrating cells in this substrate (Wichterle et al., 1997). As expected, cells from wild-type E15.5 and E18.5 explants showed robust migration (Fig. $5 B, C$ ). At E18.5, many of these cells migrated in chains (Fig. $5 C$, inset). Conversely, cells migrated less from the $D l \times 1 \ll 2^{-/-}$explants and did not form chains (Fig. 5B', $C^{\prime}$ ). Therefore, both the slice and explant assays show that the $D l x 1 \mathrm{e} 2^{-/-}$mutation results in the reduced migratory capacity of cells that ordinarily tangentially migrate along the embryonic RMS.

In vivo analysis confirms a migration defect in the Dlx $1 \leftrightarrow 2^{-/-}$ mutant embryos

The in vitro migration analyses suggest that the $D l \times 1 \mathrm{\&} 2^{-/-}$mutant cells are unable to form chains and migrate. However, it is 
possible that the environment of the mutant is disruptive to the cells and their ability to migrate. To test this possibility, we performed in vivo transplantations using either E15.5 or E18.5 dLGE from control or Dlx $\& 2^{-/-}$mutants. The cells were labeled using CellTracker dye and then transplanted into the proximal region of the RMS in wild-type adult mice. After $6 \mathrm{~d}$ of survival, both E15.5 $(n=5)$ and E18.5 $(n=4)$ control cells had migrated far along the RMS (Fig. $6 A, B$ and data not shown). However, Dlx1\& $2^{-/-}$mutant cells in both the E15.5 $(n=5)$ and E18.5 $(n=4)$ transplants remained close to the transplantation site, failing to migrate rostrally (Fig. 6 $A^{\prime}, B^{\prime}$ and data not shown). This result demonstrates the cellautonomous nature of the migration defect of Dlx $\& 2^{-/-}$mutant cells.

\section{Expression of ErbB4, Slit1, and Robo1\&2 are altered in the presumptive rostral} migratory stream of $D l x 1 \& 2^{-/-}$mutants To understand which molecules might contribute to the RMS defect in the Dlx1 \& $2^{-/-}$mutants, we examined the expression of several candidate regulatory molecules using in situ hybridization. We began our analysis at E14.5 using the expression of the vesicular GABA transporter (VGAT, Viaat) (Evans et al., 1996), to mark the location of presumptive rostral migratory stream. VGAT expression clearly shows a "corridor" of cells from the rostral the LGE to the OB (Fig. 7A). In the Dlx $1 \& 2^{-/-}$mutants, expression of VGAT is almost eliminated in the telencephalon (Fig. $\left.7 A^{\prime}\right)$.

Because of previous observations of Notch signaling in the progenitor zones in the Dlx $1 \mathrm{e} 2^{-/-} \mathrm{mu}-$ tants (Yun et al., 2002), we assessed the effect of the Dlx1 $\mho 2^{-/-}$ mutation on the expression of Hes5, a gene that is induced by Notch signaling (Ohtsuka et al., 1999). Indeed, in the Dlx $1 \& 2^{-/-}$ mutant, Hes 5 expression is increased throughout most of the progenitor zones of the subcortical telencephalon, including parts of the LGE adjacent to the OB (Fig. $7 B, B^{\prime}$ ). This finding suggests that persistent elevation of Hes5, a basic helix-loophelix transcription factor that inhibits differentiation, contributes to the inability of cells to migrate to the OB in the Dlx $1 \ll 2^{-/-}$ mutants. However, it does not address which molecules that regulate migration may be downstream of the loss of Dlx1 2 .

Previous studies have suggested that the Robo/Slit receptor/ ligand family contributes to regulating the migration of neurons to the OB (Hu and Rutishauser, 1996; Hu, 1999; Wu et al., 1999; Chen et al., 2001; Nguyen-Ba-Charvet et al., 2004; Sawamoto et al., 2006). SLIT1 acts as a repellent for tangentially migrating cells in the adult RMS (Hu and Rutishauser, 1996; Hu, 1999; Chen et al., 2001). Consistent with these findings, Slit1 $\mathrm{\&} 2^{-/-}$mutants have small olfactory bulbs (Sawamoto et al., 2006). Ordinarily, Slit1 expression flanks the SVZ corridor between the LGE and OB (Fig. 7C, arrows). However, in the Dlx1\&2 $2^{-1-}$ mutant, Slit1 ex-
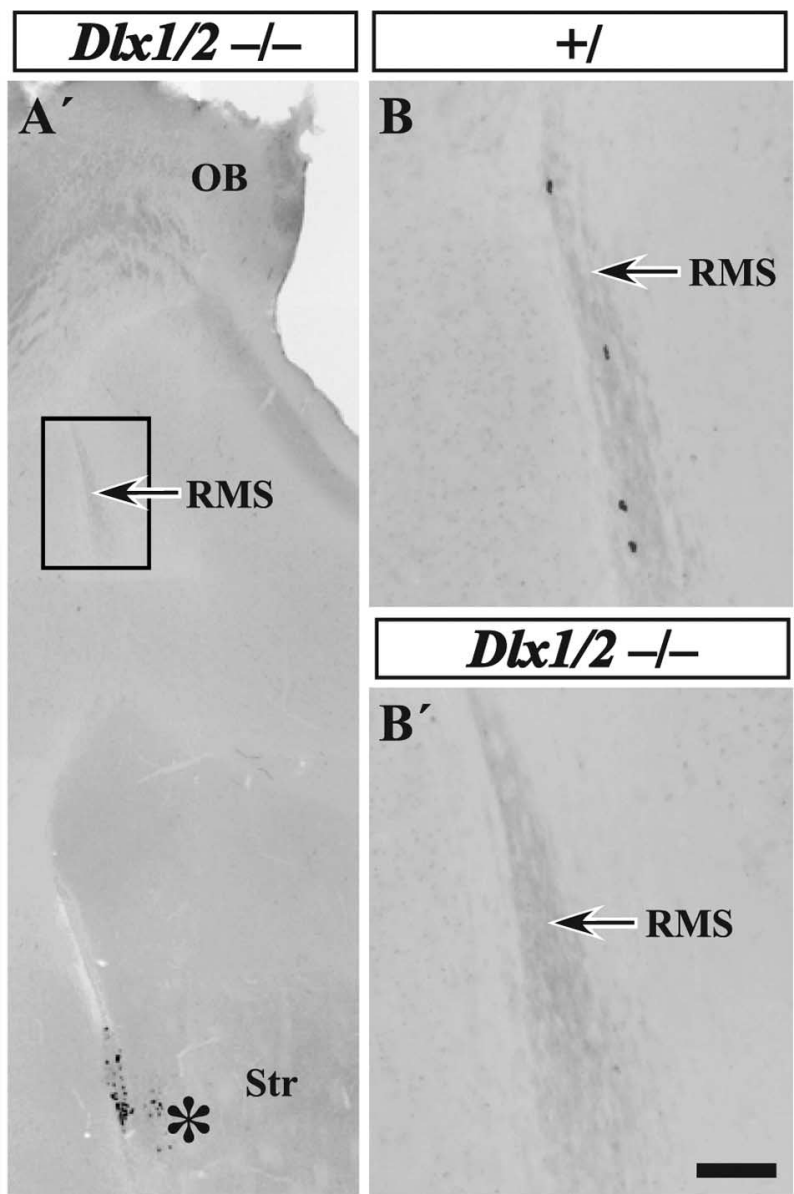

Figure 6. In vivo transplantation of $D / \times 1 \& 2^{-/-}$mutant cells into anterior SVZ of adult mice demonstrates a cell-autonomous

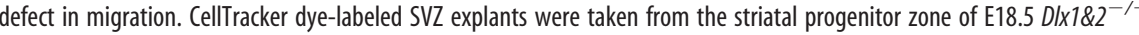
mint and control embryos and injected into the SVZ of adult mice [adjacent to the rostral striatum (Str)] with survival for $6 \mathrm{~d}$. higher-magnification view of the boxed area in $\boldsymbol{A}$ is provided in $\boldsymbol{B}$. DIx $1 \& 2^{-1-}$ mutant cells were not found anywhere outside of a very short distance away from the injection site (asterisk, $\boldsymbol{A}^{\prime}$ ). A higher-magnification view of the boxed area in $\boldsymbol{A}^{\prime}$ is provided in $\boldsymbol{B}^{\prime}$. Scale bar: $\boldsymbol{A}, \boldsymbol{A}^{\prime}, 400 \mu \mathrm{m} ; \boldsymbol{B}, \boldsymbol{B}^{\prime}, 100 \mu \mathrm{m}$.

pression is upregulated in this corridor; Slit1 ectopic expression could impede migration to the OB (Fig. $7 C^{\prime}$ ).

The expression pattern of Robo 2 is particularly intriguing with respect to migration to the OB. At E14.5, Robo2 expression is highly enriched in cells within the rostral part of the corridor leading to the $\mathrm{OB}$ (Fig. 7E, arrow). This expression is either lost or greatly reduced in the $D l x 1 \& 2^{-1-}$ mutant (Fig. $7 E^{\prime}$, arrow). Unlike Robo2, Robol is not expressed in the part of the corridor adjacent to the $\mathrm{OB}$, although it is expressed nearby within the LGE (Fig. $7 D, D^{\prime}$, arrow). These results suggest that the disruption of Robo/Slit expression may contribute to the defect in migration of the Dlx $1 \& 2^{-/-}$mutant cells. Therefore, we examined their expression more carefully in a rostral-to-caudal series of coronal sections at E18.5 (Fig. 8).

Analysis at E18.5 shows that Robo1 is expressed in the mantle of the rostral dLGE (Fig. 8J), whereas Robo2 is expressed in the SVZ of the dLGE (Fig. $8 \mathrm{~N}, \mathrm{O}$ ). In addition, further rostrally, Robo2 expression is in the RMS and SVZ of the olfactory bulb (Fig. $8 K-M$ ), whereas Robol expression encapsulates the RMS (Fig. $8 G, H$ ). In the OB, Robol expression in the SVZ is much less prominent than Robo2 (Fig. $8 F, K$ ).

In Dlx1\& $2^{-/-}$mutants at E18.5, Robo2 expression is greatly reduced in the SVZ, a portion of the mantle of the LGE (Fig. 


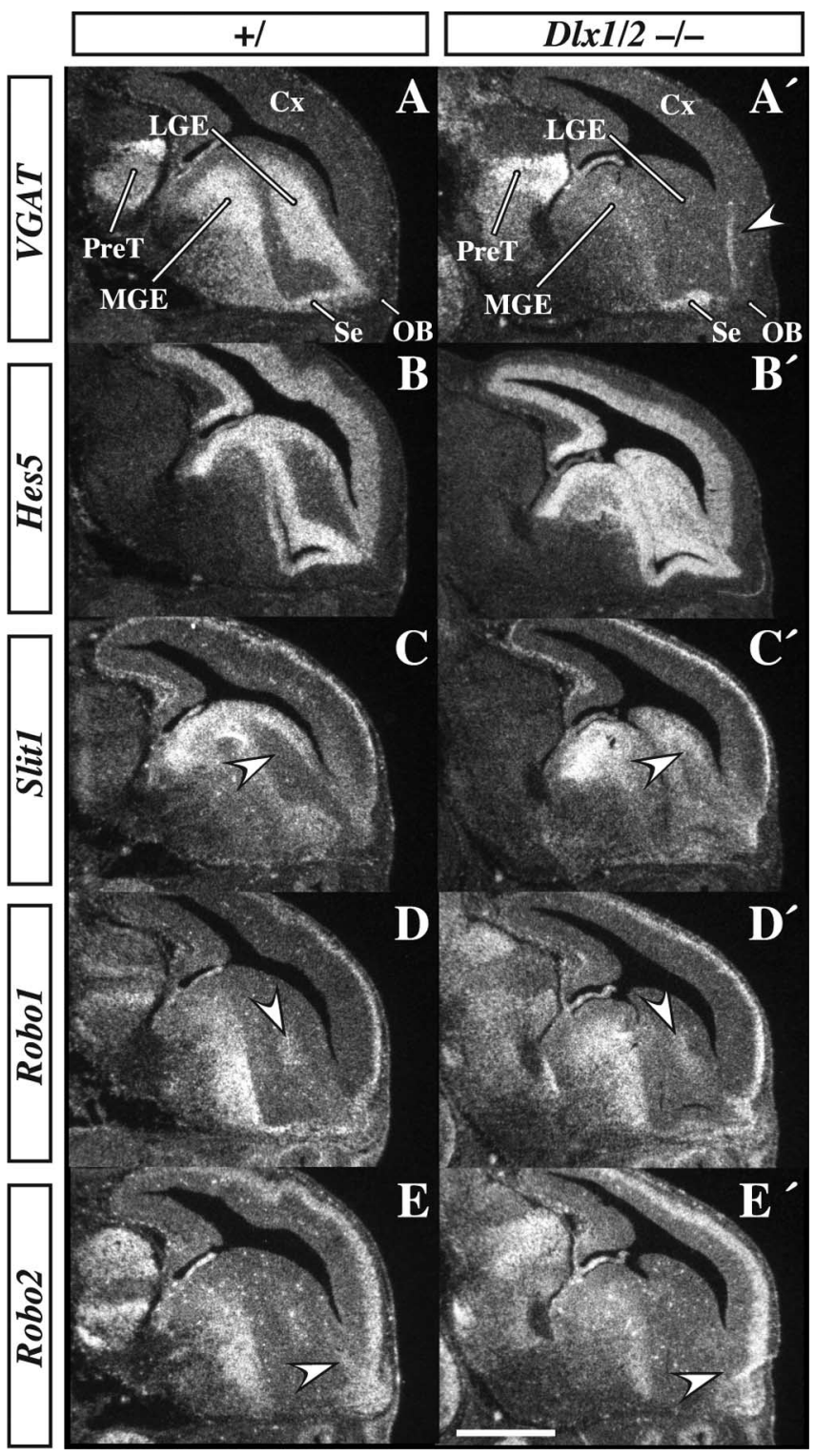

Figure 7. Radioactive in situ RNA hybridization of VGAT, Hes5, Slit1, Robo1, and Robo2 in E14.5 parasagittal DI $\times 1 \& 2^{-1-}$ mutant and control embryos. Expression of VGAT marks a corridor from the LGE to the $O B$; this expression is nearly lost from the LGE and MGE of the $D / x 1 \& 2^{-/-}$mutant embryo but is maintained in part of the septum ( $\left.\mathrm{Se} ; A, A^{\prime}\right)$. Vertical stripe (arrowhead) in cortex of $\boldsymbol{A}^{\prime}$ is a tissue fold and is not VGAT expression. Hes 5 expression, which is primarily expressed in the VZ, is increased in the SVZ of the LGE and MGE of the DIx $1 \& 2^{-\prime-}$ mutant embryo $\left(\boldsymbol{B}, \boldsymbol{B}^{\prime}\right)$. Slit1 is also ectopically expressed in the $\operatorname{SVZ}\left(\boldsymbol{C}, \boldsymbol{C}^{\prime}\right)$. Expression of Robo1 in the LGE is slightly increased (compare arrowheads in $\boldsymbol{D}$ and $\boldsymbol{D}^{\prime}$ ), whereas Robo2 expression is lost from the rostral extension of the LGE near the OB (arrowhead in $E, E^{\prime}$ ). CX, Cortex; PreT, prethalamus. Scale bar: $\boldsymbol{A}-\boldsymbol{E}^{\prime}, 300 \mu \mathrm{m}$.

$8 N^{\prime}, O^{\prime}$, arrowheads), and the RMS extension into the OB (Fig. $8 K^{\prime}, L^{\prime}$, arrowheads). Slit1 expression in the SVZ of the LGE is expanded in the Dlx1\& $2^{-/-}$mutants (Figs. $8 S^{\prime}, T^{\prime}$ ). In the RMS and $\mathrm{OB}$, its expression appears similar in the $D l \times 1 \& 2^{-/-}$mutants (Fig. $8 P^{\prime}, Q^{\prime}$ ).

Expression of ErbB4 in E18.5 control animals marks the SVZ of the dLGE (Fig. $8 C-E$, arrowheads) and its continuation into the RMS (Fig. $8 B$ ) and the SVZ of the OB (Fig. $8 A$ ). In the Dlx $1 \& 2^{-/-}$mutants, ErbB4 expression is greatly diminished in the RMS (Fig. $8 B^{\prime}$ ) and $\mathrm{OB}$ (Fig. $8 A^{\prime}$ ), whereas its expression in the SVZ of the dLGE is preserved and slightly expanded (Fig. $8 D^{\prime}, E^{\prime}$ ). Although Dlx1\&2 may promote ErbB4 expression in RMS cells, an alternative interpretation is that $\mathrm{ErbB}^{+}$cells accumulate in the dLGE attributable to the block in migration to the OB.

\section{Discussion}

Current evidence supports a model that OB projection neurons and interneurons are produced by distinct progenitor domains and express distinct sets of transcription factors (Bulfone et al., 1998). Thus, although projection neurons (glutamatergic mitral and tufted cells) are generated from the pallium and require transcription factors such as Tbr1, most interneurons (GABAergic granule and periglomerular cells) are produced by the subpallium and express transcription factors such the $D l x$ genes. Superimposed on the distinct transcription factor profile of OB projection neurons and interneurons, their progenitors share expression of some transcription factors such as Pax6 (Fig. 4) (Hack et al., 2005; Kohwi et al., 2005) and Emxl (Gorski et al., 2002) (Kohwi et al., unpublished observations). Here we investigated how Dlx1\&2 and Mash1, which encode transcription factors essential to subpallial development, control OB interneuron specification, differentiation, and migration.

\section{Dlx $1 \& 2$ and Mash1 regulate parallel pathways in OB interneuron development}

We provide evidence for parallel roles of the Dlx $\& 2$ and Mash 1 transcription factors in regulating the production, differentiation, and migration of $\mathrm{OB}$ interneurons. In the absence of Dlx1\&2, the mouse prenatal OB nearly lacks all expression of essential regulators of GABAergic function (glutamic acid decarboxylase and vesicular GABA transporter). Also, the OB mantle layer nearly lacks expression of several transcription factors, such as ER81, Pax6, and Sp8; these genes are either required or implicated in OB interneuron development (Dellovade et al., 1998; Stenman et al., 2003; Hack et al., 2005; Kohwi et al., 2005; Waclaw et al., 2006).

Conversely, Dlx1\& $2^{-/-}$mutants show overexpression of Mash1, Hes5, PK2, Sp9, and Gsh2 (Figs. 3, 7B, $B^{\prime}$ and data not shown), known regulators (or markers) of interneuron progenitors (Bulfone et al., 1998; Corbin et al., 2000; Toresson et al., 2000, 2001; Yun et al., 2001, 2003; Ng et al., 2005). This phenotype is consistent with a block in differentiation associated with elevated Notch signaling that is found in the striatal anlage of Dlxl\&2 $2^{-/-}$mutants (Yun et al., 2002).

Furthermore, $D l x 1 \& 2^{-/-}$mutants show defects in tangential migration associated with alterations in expression of molecules in three signaling pathways known to modulate OB interneuron migration (Slit/Robo, neuregulin/ErbB4, PK2/PK2 receptor) (Figs. 3EE-JJ', 7, 8) (Hu, 1999; Li et al., 1999; Chen et al., 2001; Anton et al., 2004; Nguyen-Ba-Charvet et al., 2004; $\mathrm{Ng}$ et al., 2005; Sawamoto et al., 2006). Mash1 ${ }^{-/-}$mutants also show increased $P K 2$ expression and decreased numbers of $\mathrm{OB}$ interneurons (Figs. $3 A^{\prime \prime}-V V^{\prime \prime}$ ). Thus, $D l x 1 \& 2$ and Mash1 regulate distinct pathways that promote OB interneuron development.

$D l x 1 \& 2$ are not essential for the induction of $\mathrm{OB}$ interneuron progenitors, because the $D l \times 1 \& 2^{-/-}$mutants express essential regulators of these cells (Mash1 and Gsh2) in the rostroventral telencephalic VZ (likely OB anlage) (Fig. 2 and data not shown). In addition, truncated $D l x 1$ RNA is present in the E12.5 putative OB progenitor zone in Dlx1 $2^{-/-}$mutants (Fig. $2 I^{\prime}$ ), showing that DLX1 or DLX2 protein expression is not required to induce or maintain Dlx1 RNA expression in the OB anlage. Furthermore, this result suggests that the early $\mathrm{OB}$ may be able to locally produce GABAergic interneurons and therefore may not entirely 

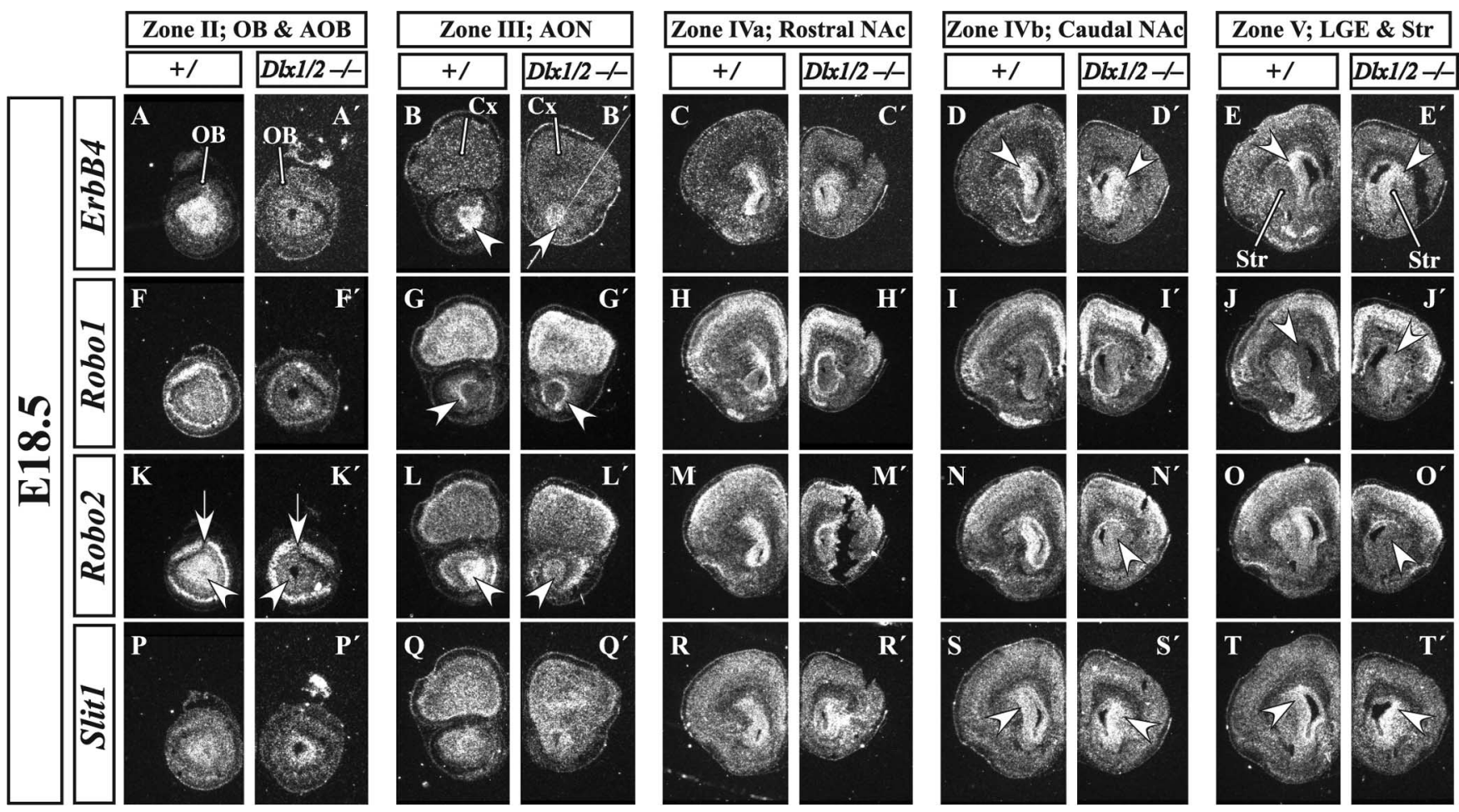

Figure 8. Radioactive in situ RNA hybridization in E18.5 coronal $D / x 1 \& 2^{-1-}$ mutant embryos shows disruption of regulatory molecule expression. ErbB4 expression in the migrating immature $O B$ interneurons is lost from the $O B$ of the $D / x 1 \& 2^{-/-}$mutant embryos $\left(A-B^{\prime}\right)$. Additional caudal sections show an increase and expansion of ErbB4 expression in the striatum of $D / x 1 \& 2^{-1-}$ mutant embryos (arrowheads in $\boldsymbol{D}-\boldsymbol{E}^{\prime}$ ). Robo 1 expression is increased in the SVZ of the striatum of the $D / x 1 \& 2^{-/-}$mutant embryo (arrowheads in $J, J^{\prime}$ ). Robo2 expression is severely reduced in the $L G E$, RMS, and OBSVZ and granule cell layers (arrowheads in $\boldsymbol{K}^{\prime}, \mathbf{L}^{\prime}, \boldsymbol{N}^{\prime}, \mathbf{O}^{\prime}$ ), whereas its expression in the mitral cell (projection neuron) layer appears normal (arrows in $\boldsymbol{K}, \boldsymbol{K}^{\prime}$ ). Slit7 expression is expanded in the SVZ and mantle of the striatum (arrowheads in $\boldsymbol{S}-\boldsymbol{T}^{\prime}$ ). (X, Cortex; Se, septum; Str, striatum. Scale bars: $\boldsymbol{A}-\boldsymbol{T}^{\prime}, 150 \mu \mathrm{m}$.

depend on tangential migration of $\mathrm{DLX}^{+}$cells from more caudal progenitor domains.

The $D l x 1 \& 2^{-/-}$mutant $\mathrm{OB}$ anlage expresses very little if any Dlx5 at E12.5, E14.5, E15.5, and E18.5 (Fig. $1 C^{\prime}, I^{\prime}$ and data not shown). However, just caudal to the $\mathrm{OB}$ anlage, there is a region associated with the septum that expresses $D l x 1,2 \& 5$ in the mantle zone (Figs. 1-3). This septal mantle zone is the only region of the telencephalon that expresses $D l x 5 \& 6$ in the absence of Dlx $\& 2$ (Figs. 1-3) (Anderson et al., 1997b; Stuhmer et al., 2002). This domain also maintains higher expression of GAD67 and VGAT compared with other subpallial regions (Figs. 2, 3, 7).

By E14.5 and E15.5, the Dlx1ß $2^{-/}$OB phenotype clearly shows a block in GABAergic differentiation. Although interneuron progenitors appear to be present, by virtue of Mash1 and Gsh 2 expression (Fig. 3 and data not shown), the OB lacks expression of GAD67 and VGAT, as well as expression of the ER81, Pax6, and Sp8 transcription factors that mark subsets of postmitotic interneurons (Fig. 3). This phenotype persists up to E18.5 (Fig. 1) (Anderson et al., 1997b; Bulfone et al., 1998); Dlx1 $2^{-/-}$ mutants die the day of birth.

Dlx $1 \ll 2^{-1-}$ mutants lack both GABAergic and dopaminergic OB interneurons (Anderson et al., 1997b; Bulfone et al., 1998). PAX6 is expressed in, and is required for, development of $\mathrm{OB}$ dopaminergic neurons (Hack et al., 2005; Kohwi et al., 2005). Dlx $1 \& 2^{-1-}$ mutants lack Pax6 ${ }^{+}$periglomerular cells at E12.5, E15.5, and E18.5 (Figs. 1-3). The Dlx1 $2^{-\prime-}$ mutants have ectopic clusters of $\mathrm{Pax}^{+}$cells caudal to the $\mathrm{OB}$ (Figs. 3, 4), suggesting that the cells are produced but fail to migrate rostrally.

Although DLX2 is coexpressed with PAX6 ${ }^{+s}$ cells in differentiating periglomerular cells, a substantial fraction of $\mathrm{PAX}^{+s}$ cells in the VZ, SVZ and MZ, caudal to the OB appear not to express DLX2 (Fig. 4).

\section{Rostral subdivisions of the subcortical telencephalon}

Morphological analyses of gene expression show abrupt changes in the molecular organization of the progenitor (VZ and SVZ) domains of the rostral subcortical telencephalon. At this point, we are uncertain about the precise number of subdivisions; for pragmatic reasons, we represent this organization in five coronal planes (zones) that are shown schematically in Figure 9. The olfactory bulb (Fig. 9, Zone I) appears to have a single progenitor domain consisting of a mosaic of molecularly distinct cell types that can be identified by DLX2 and PAX6 expression (Fig. 9). We favor the hypothesis that VZ cells expressing DLX2 (with or without PAX6) produce GABAergic interneurons; those expressing only PAX6 share properties with the pallial VZ and may produce primarily glutamatergic projection neurons (Fig. 9). These results are also supported by fate map analysis of mice expressing Dlx5/6-cAMP response element (Kohwi et al., unpublished observations).

The caudal part of the OB, zone II, is defined by the presence of the accessory olfactory bulb (Fig. 9). Zone III corresponds to a region that includes the prefrontal cortex and anterior olfactory nuclei (Fig. 9). Zones IV and V are regions with prominent parts of the septum, nucleus accumbens, and LGE; zone IV has continuous subpallial expression of ER81 and Sp8; their expression is discontinuous in zone $\mathrm{V}$.

Unlike the OB, zones II-V have multiple regionally distinct progenitor domains and exhibit migrations emanating from the pallial/subpallial boundaries containing $\mathrm{PAX}^{+}{ }^{+} \mathrm{DLX}^{+}$, and 

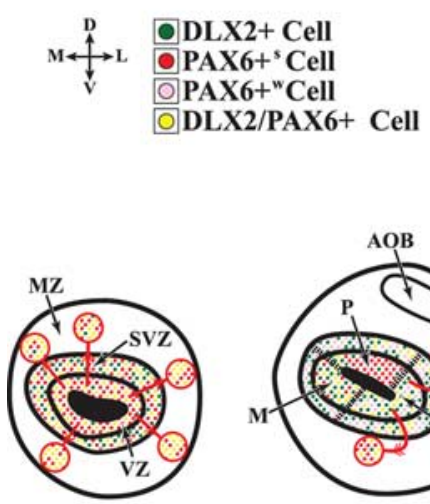

ZONE I

OB

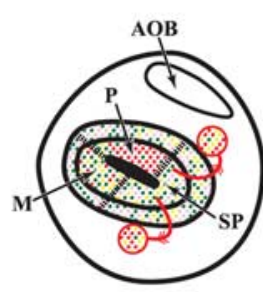

ZONE II

OB \& AOB
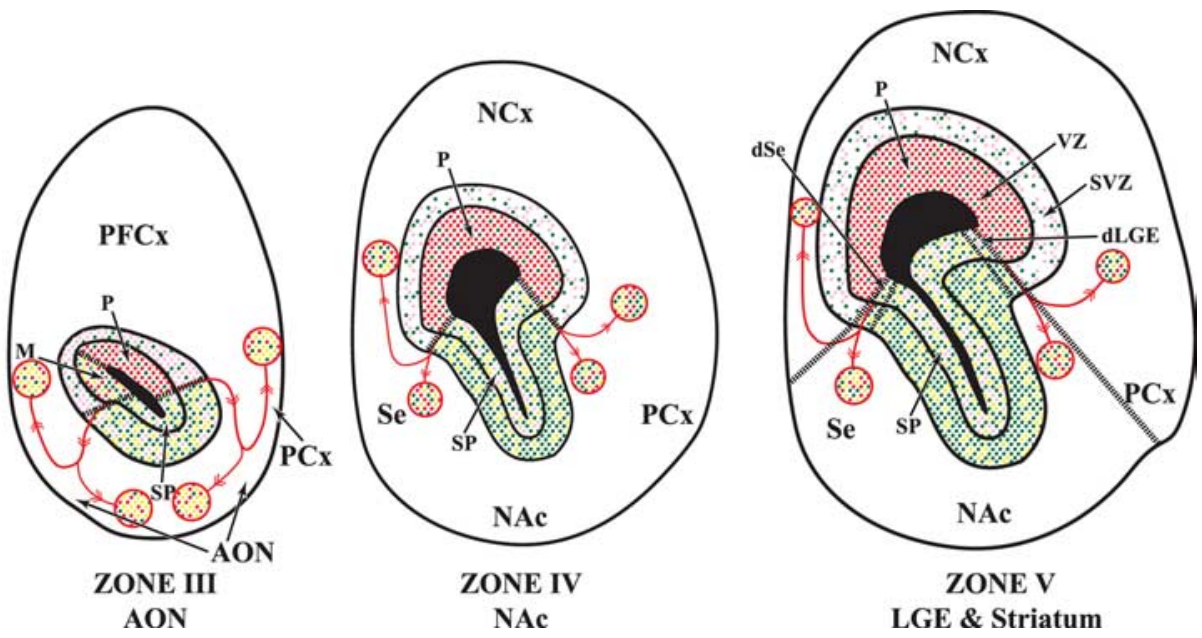

ZONE V

LGE \& Striatum

Figure 9. Schemas representing five zones of the embryonic telencephalon related to $0 B$ development. Five zones (I-V) have distinct anatomical and molecular characteristics. In each zone, only hemisections of each telencephalon is shown. The color code (top left) describes four types of DLX2 and PAX6 expression in individual nuclei. The olfactory bulb (zone I) appears to have a single progenitor domain consisting of a mixture of molecularly distinct cell types that can be identified by DLX2 and PAX6 expression. The caudal part of the OB (zone II) is defined by the presence of the $A 0 B$. Zone III corresponds to a region that includes the prefrontal cortex (PFCX) and AON. Zones IV and V are regions with prominent parts of the SE, NAC, and LGE. Unlike the OB, zones II-V have multiple progenitor domains and exhibit migrations emanating from the pallial/subpallial boundaries containing PAX6 ${ }^{+}, \mathrm{DLX2}^{+}$, and PAX6 ${ }^{+} / \mathrm{DLX2}{ }^{+}$cells. In zones II and III, PAX6 and DLX2 expression shows three types of VZ domains: pallial (P), subpallial (SP), and mixed (M) (the mixed domain is on the medial or septal side). The mixed domain most closely resembles the molecular profile of the OB VZ and forms at the medial intersection of pallial and subpallial progenitor domains. In zones IV and V, PAX6 and DLX2 labeling shows two types of VZ domains: pallial and subpallial. Zones III and IV are distinguished by the clear U-shape of the subpallial progenitor domains. We suggest that this SVZ domain corresponds to the embryonic rostral migratory stream. In DIx $1 \& 2^{-1-}$ mutants, differentiation of subpallial SVZ cells in domains II-V is defective, particularly in the embryonic RMS, resulting in loss of expression of several regulators of cell migration. NCX, Neocortex; $\mathrm{PC}$, piriform cortex; Se, septum.

$\mathrm{PAX}^{+}{ }^{+} / \mathrm{DLX} 2{ }^{+}$cells (Fig. 9). The contours of these migratory cell groups suggest that these reflect dorsal and ventral migrations into the pallium and subpallium mantle, respectively. The putative migration into the pallium could include cells that become cortical interneurons and could correspond to the postulated LGE-derived cells (Anderson et al., 2001; Wonders and Anderson, 2006). Expression of Dlx1 and GAD67 are also consistent with tangential migrations emanating from the rostrodorsal LGE to the pallium (Fig. 9).

In zones II and III, PAX6 and DLX2 expression (Fig. 9) shows three types of VZ domains: pallial, subpallial, and mixed (on the medial or septal side). The mixed domain most closely resembles the molecular profile of the OB VZ. Thus, the OB VZ may be produced at the medial intersection of pallial and subpallial progenitor domains. In zones IV and V, PAX6 and DLX2 labeling shows two types of VZ domains: pallial and subpallial (Figs. 3, 9).

Zones III and IV are distinguished by the clear U-shape of the subpallial progenitor domains and continuous expression of ER81 and Sp8 in the SVZ (Fig. 3). We suggest that this SVZ domain corresponds to the embryonic rostral migratory stream, which also exhibits prominent $D l x 1, D l \times 2, D l x 5$, Mash1, and Sp9 SVZ expression. We also suggest that the embryonic RMS is a corridor from the septum and LGE into the OB consisting primarily of SVZ cells expressing subpallial-type transcription factors and ErbB4, GAD67, PK2, and Robo2 (Figs. 1, 3, 6, 7). By E18.5, the RMS becomes encircled by cells expressing distinct set of genes, including Robol and Tbr1 (Fig. 8 and data not shown).

In zone V, ER81 and $S p 8$ expression is discontinuous, being restricted to the dLGE and dorsal septum. This suggests that, as one proceeds from zones IV to $\mathrm{V}$, there is at least one additional subpallial progenitor domain intercalated between the dLGE and dorsal septum. This domain would include ventral parts of the LGE and septum. In Dlx $1 \& 2^{-/-}$mutants, differentiation of subpallial SVZ cells in domains II-V is defective, particularly in the embryonic RMS, resulting in loss of expression of several regulators of cell migration.

\section{$D l x 1 \& 2$ are required for tangential migration of immature} GABAergic and dopaminergic neurons

Three migration assays demonstrate migration defects in cells derived from the rostral dLGE of Dlx $\& 2^{-/-}$mutants: (1) E17.5 slice cultures fail to show migration along the RMS; (2) in vitro explants from E15.5 and E18.5 dLGE fail to form migratory chains; and (3) transplants from E18.5 Dlx $1 \& 2^{-/-}$mutants into wild-type brains fail to migrate to the OB. Although we suggest that the septum also contributes OB interneurons (Long et al., 2003) (Fig. 1), we have not directly demonstrated this migration. Should it exist, it is clear that it would also be defective in delivery of GABAergic interneurons to the Dlx $1 \& 2^{-/-}$OB.

We suggest that these migratory deficits result from multiple mechanisms. SLIT expression is essential for OB morphogenesis (Sawamoto et al., 2006) and may function through a repulsive mechanism to direct migration (Hu, 1999; Li et al., 1999; Chen et al., 2001; Nguyen-Ba-Charvet et al., 2004; Sawamoto et al., 2006). Dlx1\& $2^{-1-}$ mutants show ectopic Slit1 expression along the pathway of migration to the OB, which could prevent Roboexpressing cells from migrating through this corridor (Figs. 7, 8). Indeed, Robo1 expression is maintained in this region, endowing these cells with the ability to be repelled by Slit1. Currently, the function of ROBO1\&2 is unknown in OB interneuron development.

$D l x 1 \& 2^{-/-}$mutants fail to express ErbB4 in the core of the OB and rostral aspects of the embryonic RMS. ErbB4 is implicated in mediating neuregulin 1 regulated migration and proliferation of OB interneurons (Anton et al., 2004; Ghashghaei et al., 2006). Finally, Dlx $\& 2^{-/-}$mutants overexpress $P K 2$, a secreted protein that can attract migrating OB interneurons ( $\mathrm{Ng}$ et al., 2005).

Thus, it is likely that defects in these signaling pathways, and possibly others, work together to autonomously and nonautonomously block tangential migration to the $\mathrm{OB}$ in $D l \times 1 \& 2^{-/-}$mutants. It is intriguing that the $D l \times 1 \& 2^{-/-}$mutants also exhibit a block in tangential migration from the MGE (and perhaps CGE) to the neocortex and hippocampus (Anderson et 
al., 1997b, 2001; Pleasure et al., 2001). We are uncertain about the extent to which the block in migration to the $\mathrm{OB}$ and to the neocortex/hippocampus are attributable to overlapping mechanisms. However, it is intriguing that ErbB4/neuregulin and Robo/ Slit signaling are implicated in both migrations (Anton et al., 2004; Flames et al., 2004; Andrews et al., 2006), suggesting that $D l x$ genes have a general role in regulating tangential migration of telencephalic interneurons.

\section{References}

Alcantara S, Ruiz M, D’Arcangelo G, Ezan F, de Lecea L, Curran T, Sotelo C, Soriano E (1998) Regional and cellular patterns of reelin mRNA expression in the forebrain of the developing and adult mouse. J Neurosci 18:7779-7799.

Anchan RM, Drake DP, Haines CF, Gerwe EA, LaMantia AS (1997) Disruption of local retinoid-mediated gene expression accompanies abnormal development in the mammalian olfactory pathway. J Comp Neurol 379:171-184.

Anderson SA, Eisenstat DD, Shi L, Rubenstein JL (1997a) Interneuron migration from basal forebrain to neocortex: dependence on Dlx genes. Science 278:474-476

Anderson SA, Qiu M, Bulfone A, Eisenstat DD, Meneses J, Pedersen R, Rubenstein JL (1997b) Mutations of the homeobox genes Dlx-1 and Dlx-2 disrupt the striatal subventricular zone and differentiation of late born striatal neurons. Neuron 19:27-37.

Anderson SA, Marin O, Horn C, Jennings K, Rubenstein JL (2001) Distinct cortical migrations from the medial and lateral ganglionic eminences. Development 128:353-363.

Andrews W, Liapi A, Plachez C, Camurri L, Zhang J, Mori S, Murakami F, Parnavelas JG, Sundaresan V, Richards LJ (2006) Robol regulates the development of major axon tracts and interneuron migration in the forebrain. Development 133:2243-2252.

Anton ES, Ghashghaei HT, Weber JL, McCann C, Fischer TM, Cheung ID, Gassmann M, Messing A, Klein R, Schwab MH, Lloyd KC, Lai C (2004) Receptor tyrosine kinase ErbB4 modulates neuroblast migration and placement in the adult forebrain. Nat Neurosci 7:1319-1328.

Bulfone A, Puelles L, Porteus MH, Frohman MA, Martin GR, Rubenstein JL (1993) Spatially restricted expression of Dlx-1, Dlx-2 (Tes-1), Gbx-2, and Wnt- 3 in the embryonic day 12.5 mouse forebrain defines potential transverse and longitudinal segmental boundaries. J Neurosci 13:3155-3172.

Bulfone A, Wang F, Hevner R, Anderson S, Cutforth T, Chen S, Meneses J, Pedersen R, Axel R, Rubenstein JL (1998) An olfactory sensory map develops in the absence of normal projection neurons or GABAergic interneurons. Neuron 21:1273-1282.

Casarosa S, Fode C, Guillemot F (1999) Mash1 regulates neurogenesis in the ventral telencephalon. Development 126:525-534.

Chen JH, Wen L, Dupuis S, Wu JY, Rao Y (2001) The N-terminal leucinerich regions in Slit are sufficient to repel olfactory bulb axons and subventricular zone neurons. J Neurosci 21:1548-1556.

Corbin JG, Gaiano N, Machold RP, Langston A, Fishell G (2000) The Gsh2 homeodomain gene controls multiple aspects of telencephalic development. Development 127:5007-5020.

Dellovade TL, Pfaff DW, Schwanzel-Fukuda M (1998) Olfactory bulb development is altered in small-eye (Sey) mice. J Comp Neurol 402:402-418.

Depew MJ, Liu JK, Long JE, Presley R, Meneses JJ, Pedersen RA, Rubenstein JL (1999) Dlx5 regulates regional development of the branchial arches and sensory capsules. Development 126:3831-3846.

Doetsch F, Alvarez-Buylla A (1996) Network of tangential pathways for neuronal migration in adult mammalian brain. Proc Natl Acad Sci USA 93:14895-14900.

Doetsch F, Petreanu L, Caille I, Garcia-Verdugo JM, Alvarez-Buylla A (2002) EGF converts transit-amplifying neurogenic precursors in the adult brain into multipotent stem cells. Neuron 36:1021-1034.

Eisenstat DD, Liu JK, Mione M, Zhong W, Yu G, Anderson SA, Ghattas I, Puelles L, Rubenstein JL (1999) DLX-1, DLX-2, and DLX-5 expression define distinct stages of basal forebrain differentiation. J Comp Neurol 414:217-237

Evans JE, Frostholm A, Rotter A (1996) Embryonic and postnatal expres- sion of four gamma-aminobutyric acid transporter mRNAs in the mouse brain and leptomeninges. J Comp Neurol 376:431-446.

Flames N, Long JE, Garratt AN, Fischer TM, Gassmann M, Birchmeier C, Lai C, Rubenstein JL, Marin O (2004) Short- and long-range attraction of cortical GABAergic interneurons by neuregulin-1. Neuron 44:251-261.

Ghashghaei HT, Weber J, Pevny L, Schmid R, Schwab MH, Lloyd KC, Eisenstat DD, Lai C, Anton ES (2006) The role of neuregulin-ErbB4 interactions on the proliferation and organization of cells in the subventricular zone. Proc Natl Acad Sci USA 103:1930-1935.

Gorski JA, Talley T, Qiu M, Puelles L, Rubenstein JL, Jones KR (2002) Cortical excitatory neurons and glia, but not GABAergic neurons, are produced in the Emx1-expressing lineage. J Neurosci 22:6309-6314.

Hack I, Bancila M, Loulier K, Carroll P, Cremer H (2002) Reelin is a detachment signal in tangential chain-migration during postnatal neurogenesis. Nat Neurosci 5:939-945.

Hack MA, Saghatelyan A, de Chevigny A, Pfeifer A, Ashery-Padan R, Lledo PM, Gotz M (2005) Neuronal fate determinants of adult olfactory bulb neurogenesis. Nat Neurosci 8:865-872.

Herrera DG, Garcia-Verdugo JM, Alvarez-Buylla A (1999) Adult-derived neural precursors transplanted into multiple regions in the adult brain. Ann Neurol 46:867-877.

Horton S, Meredith A, Richardson JA, Johnson JE (1999) Correct coordination of neuronal differentiation events in ventral forebrain requires the bHLH factor MASH1. Mol Cell Neurosci 14:355-369.

Hu H (1999) Chemorepulsion of neuronal migration by Slit2 in the developing mammalian forebrain. Neuron 23:703-711.

$\mathrm{Hu} \mathrm{H}$, Rutishauser U (1996) A septum-derived chemorepulsive factor for migrating olfactory interneuron precursors. Neuron 16:933-940.

Inoue T, Nakamura S, Osumi N (2000) Fate mapping of the mouse prosencephalic neural plate. Dev Biol 219:373-383.

Jimenez D, Garcia C, de Castro F, Chedotal A, Sotelo C, de Carlos JA, Valverde F, Lopez-Mascaraque L (2000) Evidence for intrinsic development of olfactory structures in Pax-6 mutant mice. J Comp Neurol 428:511-526.

Kohwi M, Osumi N, Rubenstein JL, Alvarez-Buylla A (2005) Pax6 is required for making specific subpopulations of granule and periglomerular neurons in the olfactory bulb. J Neurosci 25:6997-7003.

Kuwajima T, Nishimura I, Yoshikawa K (2006) Necdin promotes GABAergic neuron differentiation in cooperation with Dlx homeodomain proteins. J Neurosci 26:5383-5392.

Li HS, Chen JH, Wu W, Fagaly T, Zhou L, Yuan W, Dupuis S, Jiang ZH, Nash W, Gick, C. et al (1999) Vertebrate slit, a secreted ligand for the transmembrane protein roundabout, is a repellent for olfactory bulb axons. Cell 96:807-818.

Lois C, Alvarez-Buylla A (1994) Long-distance neuronal migration in the adult mammalian brain. Science 264:1145-1148.

Lois C, Garcia-Verdugo JM, Alvarez-Buylla A (1996) Chain migration of neuronal precursors. Science 271:978-981.

Long JE, Garel S, Depew MJ, Tobet S, Rubenstein JL (2003) DLX5 regulates development of peripheral and central components of the olfactory system. J Neurosci 23:568-578.

Lopez-Mascaraque L, de Castro F (2002) The olfactory bulb as an independent developmental domain. Cell Death Differ 9:1279-1286.

Luskin MB (1993) Restricted proliferation and migration of postnatally generated neurons derived from the forebrain subventricular zone. Neuron 11:173-189.

Luskin MB, Boone MS (1994) Rate and pattern of migration of lineallyrelated olfactory bulb interneurons generated postnatally in the subventricular zone of the rat. Chem Senses 19:695-714.

Marin O, Rubenstein JL (2001) A long, remarkable journey: tangential migration in the telencephalon. Nat Rev Neurosci 2:780-790.

Marin O, Rubenstein JL (2003) Cell migration in the forebrain. Annu Rev Neurosci 26:441-483.

Marin O, Anderson SA, Rubenstein JL (2000) Origin and molecular specification of striatal interneurons. J Neurosci 20:6063-6076.

Ng KL, Li JD, Cheng MY, Leslie FM, Lee AG, Zhou QY (2005) Dependence of olfactory bulb neurogenesis on prokineticin 2 signaling. Science 308:1923-1927.

Nguyen-Ba-Charvet KT, Picard-Riera N, Tessier-Lavigne M, Baron-Van Evercooren A, Sotelo C, Chedotal A (2004) Multiple roles for slits in the control of cell migration in the rostral migratory stream. J Neurosci 24:1497-1506. 
Nomura T, Osumi N (2004) Misrouting of mitral cell progenitors in the Pax6/small eye rat telencephalon. Development 131:787-796.

Nomura T, Holmberg J, Frisen J, Osumi N (2006) Pax6-dependent boundary defines alignment of migrating olfactory cortex neurons via the repulsive activity of ephrin A5. Development 133:1335-1345.

Ohtsuka T, Ishibashi M, Gradwohl G, Nakanishi S, Guillemot F, Kageyama R (1999) Hes1 and Hes5 as notch effectors in mammalian neuronal differentiation. EMBO J 18:2196-2207.

Parras CM, Schuurmans C, Scardigli R, Kim J, Anderson DJ, Guillemot F (2002) Divergent functions of the proneural genes Mash1 and Ngn2 in the specification of neuronal subtype identity. Genes Dev 16:324-338.

Parras CM, Galli R, Britz O, Soares S, Galichet C, Battiste J, Johnson JE, Nakafuku M, Vescovi A, Guillemot F (2004) Mash1 specifies neurons and oligodendrocytes in the postnatal brain. EMBO J 23:4495-4505.

Pleasure SJ (2001) An arrow hits the Wnt signaling pathway. Trends Neurosci 24:69-71.

Porteus MH, Bulfone A, Liu JK, Puelles L, Lo LC, Rubenstein JL (1994) DLX-2, MASH-1, and MAP-2 expression and bromodeoxyuridine incorporation define molecularly distinct cell populations in the embryonic mouse forebrain. J Neurosci 14:6370-6383.

Puelles L, Kuwana E, Puelles E, Bulfone A, Shimamura K, Keleher J, Smiga S, Rubenstein JL (2000) Pallial and subpallial derivatives in the embryonic chick and mouse telencephalon, traced by the expression of the genes Dlx-2, Emx-1, Nkx-2.1, Pax-6, and Tbr-1. J Comp Neurol 424:409-438.

Qiu M, Bulfone A, Martinez S, Meneses JJ, Shimamura K, Pedersen RA, Rubenstein JL (1995) Null mutation of Dlx-2 results in abnormal morphogenesis of proximal first and second branchial arch derivatives and abnormal differentiation in the forebrain. Genes Dev 9:2523-2538.

Qiu M, Bulfone A, Ghattas I, Meneses JJ, Christensen L, Sharpe PT, Presley R, Pedersen RA, Rubenstein JL (1997) Role of the Dlx homeobox genes in proximodistal patterning of the branchial arches: mutations of Dlx-1, Dlx-2, and Dlx-1 and -2 alter morphogenesis of proximal skeletal and soft tissue structures derived from the first and second arches. Dev Biol 185:165-184.

Rutishauser U (1996) Polysialic acid and the regulation of cell interactions. Curr Opin Cell Biol 8:679-684.

Sawamoto K, Wichterle H, Gonzalez-Perez O, Cholfin JA, Yamada M, Spassky N, Murcia NS, Garcia-Verdugo JS, Marin O, Rubenstein JLR, Tessier-Lavigne M, Okano H, Alvarez-Buylla A (2006) Subventricular neuroblasts follow the flow of cerebrospinal fluid in the adult brain. Science 311:629-632.

Stenman J, Toresson H, Campbell K (2003) Identification of two distinct progenitor populations in the lateral ganglionic eminence: implications for striatal and olfactory bulb neurogenesis. J Neurosci 23:167-174.
Stoykova A, Gruss P (1994) Roles of Pax-genes in developing and adult brain as suggested by expression patterns. J Neurosci 14:1395-1412.

Stuhmer T, Anderson SA, Ekker M, Rubenstein JL (2002) Ectopic expression of the Dlx genes induces glutamic acid decarboxylase and Dlx expression. Development 129:245-252.

Sussel L, Marin O, Kimura S, Rubenstein JL (1999) Loss of Nkx2.1 homeobox gene function results in a ventral to dorsal molecular respecification within the basal telencephalon: evidence for a transformation of the pallidum into the striatum. Development 126:3359-3370.

Toresson H, Campbell K (2001) A role for Gsh1 in the developing striatum and olfactory bulb of Gsh2 mutant mice. Development 128:4769-4780.

Toresson H, Potter SS, Campbell K (2000) Genetic control of dorsal-ventral identity in the telencephalon: opposing roles for Pax6 and Gsh2. Development 127:4361-4371.

Tucker ES, Polleux F, Lamantia AS (2006) Position and time specify the migration of a pioneering population of olfactory bulb interneurons. Dev Biol 297:387-401.

Waclaw RR, Allen II ZJ, Bell SM, Erdelyi F, Szabo G, Potter SS, Campbell K (2006) The zinc finger transcription factor Sp8 regulates the generation and diversity of olfactory bulb interneurons. Neuron 49:503-516.

Wichterle H, Garcia-Verdugo JM, Alvarez-Buylla A (1997) Direct evidence for homotypic, glia-independent neuronal migration. Neuron 18:779-791.

Wonders CP, Anderson SA (2006) The origin and specification of cortical interneurons. Nat Rev Neurosci 7:687-696.

Wu W, Wong K, Chen J, Jiang Z, Dupuis S, Wu JY, Rao Y (1999) Directional guidance of neuronal migration in the olfactory system by the protein Slit. Nature 400:331-336.

Yun K, Potter S, Rubenstein JL (2001) Gsh2 and Pax6 play complementary roles in dorsoventral patterning of the mammalian telencephalon. Development 128:193-205.

Yun K, Fischman S, Johnson J, Hrabe de Angelis M, Weinmaster G, Rubenstein JL (2002) Modulation of the notch signaling by Mash 1 and Dlx1/2 regulates sequential specification and differentiation of progenitor cell types in the subcortical telencephalon. Development 129:5029-5040.

Yun K, Garel S, Fischman S, Rubenstein JL (2003) Patterning of the lateral ganglionic eminence by the Gsh1 and Gsh2 homeobox genes regulates striatal and olfactory bulb histogenesis and the growth of axons through the basal ganglia. J Comp Neurol 461:151-165.

Zerucha T, Stuhmer T, Hatch G, Park BK, Long Q, Yu G, Gambarotta A, Schultz JR, Rubenstein JL, Ekker M (2000) A highly conserved enhancer in the Dlx5/Dlx6 intergenic region is the site of cross-regulatory interactions between Dlx genes in the embryonic forebrain. J Neurosci 20:709-721. 